\title{
1 Changes in excitability and ion channel expression in neurons of the major pelvic ganglion in female type II diabetic mice
}

3

4
Michael Gray $^{{ }^{*}}$, Kawasi M. Lett ${ }^{1 *}$, Virginia B. Garcia ${ }^{1}$, Cindy W. Kyi ${ }^{1}$, Kathleen A. Pennington ${ }^{2}$, Laura C. Schulz ${ }^{2}$, David J. Schulz ${ }^{1}$

${ }^{1}$ Division of Biological Sciences, University of Missouri, Columbia, MO USA 65211

${ }^{2}$ Department of Obstetrics, Gynecology and Women's Health, University of Missouri, Columbia, MO, 65211, USA.

* Denotes equal contribution by these authors

\section{Corresponding Author}

David J. Schulz, Ph.D.

Division of Biological Sciences

University of Missouri-Columbia

218 LeFevre Hall

Columbia, MO 65211

Ph 573-882-4067

Fax 573-884-5020

Email: schulzd@missouri.edu

\section{Acknowledgments}

This work was funded by a grant from the Missouri Spinal Cord Injuries Research Program (D.J.S.), the Craig H. Neilsen Foundation (D.J.S.), American Diabetes Association Grant 1-14-BS-181 (L.C.S.) and American Heart Association Postdoctoral Fellowship 13POST16910108 (K.A.P.). The authors declare no competing financial interests. 


\section{ABSTRACT}

Bladder cystopathy is a common urological complication of diabetes, and has been associated with changes in parasympathetic ganglionic transmission and some measures of neuronal excitability in male mice. To determine whether type II diabetes also impacts excitability of parasympathetic ganglionic neurons in females, we investigated neuronal excitability and firing properties, as well as underlying ion channel expression, in major pelvic ganglion (MPG) neurons in control, 10-week, and 21-week db/db mice. Type II diabetes in $L e p r^{d b / d b}$ animals caused a non-linear change in excitability and firing properties of MPG neurons. At 10 weeks, cells exhibited increased excitability as demonstrated by an increased

42 likelihood of firing multiple spikes upon depolarization, decreased rebound spike latency, and overall

43 narrower action potential half-widths as a result of increased depolarization and repolarization slopes.

44 Conversely, at 21 weeks MPG neurons of $\mathrm{db} / \mathrm{db}$ mice reversed these changes, with spiking patterns and

45 action-potential properties largely returning to control levels. These changes are associated with

46 numerous time-specific changes in calcium, sodium, and potassium channel subunit mRNA levels.

47 However, Principal Components Analysis of channel expression patterns revealed that the rectification of

48 excitability is not simply a return to control levels, but rather a distinct ion channel expression profile in

49 21-week $\mathrm{db} / \mathrm{db}$ neurons. These data indicate that type II diabetes can impact the excitability of post-

50 ganglionic, parasympathetic bladder-innervating neurons of female mice, and suggest that the non-linear

51 progression of these properties with diabetes may be the result of compensatory changes in channel

52 expression that act to rectify disrupted firing patterns of db/db MPG neurons.

54 Keywords: type II diabetes, diabetic cystopathy, autonomic ganglia, parasympathetic neurons, 


\section{INTRODUCTION}

Diabetes is a systemic, progressive disease characterized by lack of insulin directly (Type I), or functional lack of its effectors and/or insulin resistance (Type II), that ultimately leads to hyperglycemia and chronic complications. Diabetes is the seventh leading cause of death in the United States and afflicts $11.1-11.9 \%$ of adults over the age of 20 ; this rate has increased from $8.9 \%$ in years $1988-1994$ to $11.9 \%$ in years 2011-2014 (United States. Department of Health and Human Services. et al. 2016). In addition, diabetic complications are age dependent (Gunnarsson 1975; DCCT Research Group 1996; Liu et al. 2017). This age dependence combined with the $111.5 \%$ increase in persons age 65 and older from 19752015 (United States. Department of Health and Human Services. et al. 2016), necessitates studying an important complication of diabetes—diabetic neuropathy.

Diabetic neuropathy is particularly dangerous due to its insidious development, susceptibility of autonomic neurons and their subsequent regulation of vital organ systems, and a potential for positive feedback loops through dysregulation of microvasculature (Faerman et al. 1971; Vinik et al. 2003). Interventions are difficult as symptoms are subclinical and are often undiagnosed until long after neural lesions occur. That is, autonomic motor neuron damage occurs long before patients report somatic sensory symptoms. This is supported by the finding that in diabetic mice, thin, non-myelinated post ganglionic autonomic motor neurons show deficits long before somatic sensory motorneurons do (Liu et al. 2017). Neuropathic lesions can affect various autonomic pathways resulting in gastroparesis (Vinik et al. 2003), cardiovascular dysregulation (Vinik et al. 2003, 2011), sudomotor dysfunction (Liu et al. 2017), diabetic cystopathy (Faerman et al. 1971; Frimodt-Moller 1980; Kaplan et al. 1995; Vinik et al. 2003), and dysregulation of blood flow in the periphery (UKPDS 1998). Bladder dysfunction as a result of diabetes (i.e. diabetic cystopathy) is characterized by reduced bladder sensation, increased post-residual void volume and overactive bladder (Kaplan et al. 1995; Yuan et al. 2015), and was first formally described in diabetics in 1864 (Faerman et al. 1971). Some of the effects of diabetic cystopathy can be attributed to damaged bladder afferents. For example, it has been shown in streptozocin (STZ) treated rats 
83 (type I diabetes model) that diabetic cystopathy is correlated with reduced levels of nerve growth factor

84 (NGF) in dorsal root ganglion neurons (Sasaki et al. 2002). Furthermore, when NGF is expressed at the

85 bladder wall, the development of diabetic cystopathy and subsequent increased post residual void volume

86 can be mitigated (Sasaki et al. 2004). However, little is known as to how diabetes impacts autonomic

87 neurons innervating the bladder, and how this contributes to autonomic neuropathy and bladder

88 cystopathy.

The major pelvic ganglion (MPG) of the mouse is the primary motor innervation of the urinary post-synaptic potentials (EPSP) up to 20 seconds after pelvic nerve stimulation relative to control.

93 Simultaneously, the authors observed no change in EPSP amplitude. However, STZ-treated mice did not

94 differ in EPSP number and had significantly reduced amplitudes relative to control mice. This suggests

95 that the type I and type II models are distinct in how they affect physiology of MPG neurons.

96 Furthermore, change in action potential properties is similarly dependent on diabetic type: after-

97 hyperpolarization (AHP) duration was significantly decreased in $\operatorname{Lepr}^{\mathrm{db} / \mathrm{db}}$ mice, while being significantly

98 increased in STZ mice (Tompkins et al. 2013). Finally, MPG neuron input resistance and resting

99 membrane potential are decreased and depolarized, respectively, in Lepr ${ }^{\mathrm{db} / \mathrm{db}}$ mice but unaffected in STZ

100 mice (Tompkins et al. 2013). These results suggest that both EPSP and intrinsic properties of MPG

101 neurons are differentially modulated by the nature of the diabetic model.

In this study, we exploit the Lepr ${ }^{\mathrm{db} / \mathrm{db}}$ C57BL/6J mouse, to extend our understanding of how type

103 II diabetes affects progression of changes in neuronal excitability in neurons of the MPG of female mice.

104 Specifically, we examine how these conditions change neurons at 10- and 21-week time points by

105 combining current clamp recordings of neuronal output with ion channel expression analyses in the

106 MPGs of female mice. We predicted that firing properties and intrinsic properties should resemble that

107 observed by Tompkins et al. (2013); with a general increase in excitability at week 21 to evoked firing 
rate, an increased RMP, decreased input resistance, and increased AHP duration. However, we observed a

109 distinct effect: excitability of MPG neurons was initially increased at 10-weeks, but subsequently became

110 less excitable again - towards baseline levels - at 21-weeks. These results suggest a compensatory change

111 in MPG neurons in diabetic animals. We then went on to investigate potential underlying mechanisms for

112 these changes via measuremnts of ion channel mRNA levels in MPGs from 10-week and 21-week

113 diabetic females.

\section{METHODS}

Type II Diabetes Model - Lepr ${ }^{d b / d b}$ Animals

Wild type (WT) C57BL/6J and Lepr ${ }^{\mathrm{db} / \mathrm{db}}$ female mice (Mus musculus) were obtained from the

118 Jackson Laboratory (Bar Harbor, ME, USA). Lepr $^{\mathrm{db} / \mathrm{db}}$ mice have a mutation that interrupts the longest

119 isoform of the leptin receptor (Chen et al. 1996). These animals display hyperphagia, obesity,

120 hyperglycemia and hyperinsulinemia, which has led to their widespread use as a model of type II

121 diabetes. Together, mouse and rat leptin mutants have been used in over 4000 published studies of type II

122 diabetes (Wang et al. 2014). Lepr $^{\mathrm{db} / \mathrm{db}}$ mice have been used by the Animal Models of Diabetic

123 Complications Consortium and others as models for diabetic neuropathy (Sullivan et al. 2007).

Mice were group housed in cages on a $12 \mathrm{hr}$. light/dark cycle and fed a standard chow diet ad

125 libitum. All animal procedures were performed in accordance with National Institutes of Health Guide for

126 the Care and Use of Laboratory Animals and approved by the University of Missouri Animal Care and

127 Use Committee. 
Glucose Measurement. At either $10\left(\mathrm{n}=15 \mathrm{WT}\right.$ and $\left.14 \mathrm{Lepr}^{\mathrm{db} / \mathrm{db}}\right)$ or $21(\mathrm{n}=6 \mathrm{WT}$ and 14

131 Lepr $^{\mathrm{db} / \mathrm{db}}$ ) weeks of age animals were fasted for 4 hours and then a fasting glucose measurement was taken 132 via tail blood using the average of two readings of a OneTouch ${ }^{\circledR}\left(\right.$ Sunnyvale, CA) or ReliOn Prime ${ }^{\circledR}$

133 (Arkay inc., Kyoto, Japan; Distributed by Walmart, Bentonville, AR) Blood Glucose Monitoring System.

134 At this time blood was collected to measure fasting serum insulin levels. Weights were also recorded at 135 this time.

Insulin Elisa. Serum insulin levels were analyzed using a Mouse/Rat Insulin Elisa (Millipore ${ }^{\mathrm{TM}}$,

137 Billerica, MA) according to manufacturer's instructions. A total number of 6 samples at 10 weeks were

138 run for both WT and Lepr ${ }^{\mathrm{db} / \mathrm{db}}$ females. At 21 weeks of age 9 Lepr $^{\mathrm{db} / \mathrm{db}}$ and 6 WT females were analyzed.

139 For Lepr ${ }^{\mathrm{db} / \mathrm{db}}$ serum was diluted at 1:20 with matrix solution provided in the ELSIA kit to allow for 140 measurements to fall on the standard curve.

Electrophysiology

MPGs were dissected from isoflurane euthanized female mice from wildtypes $(n=9)$ at 10 weeks

144 (WT), Lepr ${ }^{\mathrm{db} / \mathrm{db}}$ at 10 weeks $\left(\mathrm{n}=5\right.$; DB10), or Lepr $^{\mathrm{db} / \mathrm{db}}$ at 21 weeks $(\mathrm{n}=5$; DB21). Dissection and all 145 experiments were done in oxygenated physiological saline at room temperature. MPGs were dissected out 146 and pinned to a Sylgard (Dow, Midland, MI) lined perfusion chamber. The preparation was then 147 desheathed using small pins to remove excess tissue. Saline was composed of in mM: $\mathrm{NaCl}, 146 ; \mathrm{KCl}$, 148 4.7; $\mathrm{MgSO}_{4}, 0.6 ; \mathrm{NaHCO}_{3}, 1.6 ; \mathrm{NaH}_{2} \mathrm{PO}_{4}, 0.13 ; \mathrm{CaCl}_{2}, 2.5$; Glucose, 7.8; HEPES, 20; pH'd to 7.3.

149 Electrodes were pulled on a P-97 microelectrode puller (Sutter, Novato, CA) filled with 3M KCl, and had 150 resistances of 30 to $60 \mathrm{M} \Omega$. Recordings were acquired in Bridge mode using an Axoclamp 900A and 151 digitized using a Digidata 1440A using the pClamp 10.3 suite of software (Molecular Devices, 152 Sunnyvale, Ca) running on an IBM-compatible computer. Silver electrode and ground wire were 153 chlorided using household Bleach (Clorox, Oakland, CA). 
Passive properties. Resistance, time constant, capacitance and rebound spikes were estimated

156 from -500 pA current injections of $400 \mathrm{~ms}$. In some protocols where there were no rebound spikes, these

157 properties were estimated from $-500 \mathrm{pA}$ current injections for $2000 \mathrm{~ms}$, To ensure these protocols did not 158 differ, we examined action potential properties for 12 WT neurons where both protocols were used. A 159 paired t-test showed that hyperpolarization duration did not significantly affect these measurements, the closest measurement to being affected was AHP $(\mathrm{t}(11)=2.090, \mathrm{p}=0.061)$ while all other properties were unaffected $(\mathrm{p}>0.1)$. Due to the contamination of slow activating currents and membranes being nonisopotential in real neurons, time was estimated by the 2 exponential fit; $V_{m}(t)=V_{\text {final }}+A_{1} e^{-t / \tau_{1}}+$ $A_{2} e^{-t / \tau_{2}}$; the larger A (IR) and time constant term were taken to be the time constant (Golowasch et al. 2009; White and Hooper 2013). Capacitance was estimated from this time constant and input resistance. For excitability data, current was injected from 0 to $700 \mathrm{pA}$ in $50 \mathrm{pA}$ steps for $400 \mathrm{~ms}$. statistics package of the Clampfit program from the pClamp 10.3 suite of software (Molecular Devices, Sunnyvale, Ca) (All others). These properties are illustrated in figure 1 for reference, and unless otherwise stated were performed on rebound spikes to prevent contamination from current injection. from passive properties and rheobase. First, we extrapolated manually from step protocols. Second, we 173 adopted an adapted version of the spike slope method, where the derivative of voltage with respect to time 174 slope is plotted vs voltage and the voltage at which this slope meets or exceeds some slope is threshold 175 usually set from 2 to $20 \mathrm{mV} / \mathrm{ms}$ (Naundorf et al. 2006; Platkiewicz and Brette 2010, 2011). However, rather than using constant ascending spike slope, this method was adapted by measuring maximal

177 ascending slope within a $0.5 \mathrm{~ms}$ bin, defining threshold as the voltage recorded $0.25 \mathrm{~ms}$ before the center 
method $(M=-23.5, S D=8.1)$ and manual estimation $(M=-23.5, S D=8.1)$. Slope method was chosen to minimize any confounds between changes in ascending slope.

Inclusion Criterion. Some neurons impaled produced no spikes. As we could not ascertain whether this was due to impalement damage, or these cells being silent neurons or closely apposed satellite glial cells (Hanani 2010), the following inclusion criteria were made: 1) All neurons must produce spikes to depolarizing current injections. 2) All cells must have resting membrane potentials less than $-30 \mathrm{mV}$. 3) All cells must have input resistances greater than $\sim 18 \mathrm{M} \Omega$. Statistics and graphs were made in Sigmaplot 11.0 (Chicago, Il), R (https://www.r-project.org/) and formatted in Adobe Illustrator CC 2017 (San Jose, CA). Data that passed normality testing and were shown to be homoscedastic were analyzed using one-way ANOVA. Most Data, however, was found to be non-normal and /or fail equal variance and comparisons were therefore made with a non-parametric

191 Kruskal-Wallis one-way ANOVA on ranks using a post-hoc Dunn's test. The two-way ANOVA for 192 Figure 3B failed the assumptions of normality and homoscedasticity and could not be successfully 193 transformed, statistics are reported for raw data.

Paired MPGs from each animal were collected into Trizol reagent (Life Technologies, Carlsbad,

197 CA), homogenized, and stored at $-80^{\circ} \mathrm{C}$ until RNA extraction. Total RNA was isolated from MPGs

198 according to the protocol provided by the manufacturer. Complementary DNA (cDNA) was generated

199 from 100 ng total RNA primed by a mixture of random hexamers and oligo-dT primers. Reverse

200 transcription reactions were carried out at a volume of $20 \mu \mathrm{l}$ using qScript cDNA SuperMix (QuantaBio,

201 Beverly, MA) according to manufacturer protocols. Following cDNA synthesis, the reaction was heat inactivated and diluted $5 \mathrm{X}$ to a final volume of $100 \mu \mathrm{l}$ before being used as a template for quantitative 
PCR (qPCR). From each cDNA reaction we quantified at least 15 different gene products. Multiple

204

205 cDNA synthesis reactions were carried out from a single total RNA sample to quantify the full suite of genes examined in this study.

In our previous work, we designed or modified and independently validated qPCR primers for use in absolute quantitation of mRNA copy number for all of the genes of interest in this study. These primer sets are previously published, and standard curves generated and used as described in our previous work (Garcia et al. 2014, 2018). Briefly, qPCR reactions were carried out using SYBR mastermix (BioRad) according to the manufacturer's instructions, and consisted of primers at final concentrations of $2.5 \mu \mathrm{M}$. Reactions were carried out on a CFXConnect (BioRad) machine with a three-step cycle of $95^{\circ} \mathrm{C}$ $15 \mathrm{~s}, 58^{\circ} \mathrm{C}-20 \mathrm{~s}, 72^{\circ} \mathrm{C}-20 \mathrm{~s}$, followed by a melt curve from $65^{\circ} \mathrm{C}$ to $95^{\circ} \mathrm{C}$. Fluorescence data acquisition was made at the $72^{\circ} \mathrm{C}$ step, and every $0.5^{\circ} \mathrm{C}$ of the melt curve. All reactions were run in triplicate, and the average $\mathrm{Ct}$ (cycle threshold) was used for interpolation with standard curves to generate copy number for a given reaction.

The unit we use to express all of the qPCR data in this study is "copy number per ng of total RNA," and reflects the amount of input RNA that went into the cDNA synthesis reaction. All of the data were normalized (see Garcia et al. 2014) relative to the average expression of Glyceraldehyde 3phosphate dehydrogenase (GAPDH), beta-actin, and hypoxanthine guanine phosphoribosyl transferase (HPRT) genes from each sample (Vandesompele et al. 2002). Samples that were found to have low expression of these control genes were eliminated from the analysis. None of the control genes showed significant differences in expression across groups.

\section{RESULTS}

Lepr ${ }^{d b / d b}$ mice produce a diabetic phenotype with hyperglycemia that differs according to age. Diabetic neuropathy and the metabolic derangements of diabetes itself (Gunnarsson 1975; Giachetti 1978; Medici 
et al. 1999) are age-dependent. Therefore, we wanted to verify that our Lepr $^{\mathrm{db} / \mathrm{db}}$ model exhibited diabetic physiological properties such as weight gain, elevated blood sugar and serum insulin to verify our diabetic model had sufficient time to develop the phenotype.

Lepr $^{d b / d b}$ mice are heavier than WT. Mean weights (Figure 2A) for diabetic mice from weeks 10 to 21, increased from $44.1 \mathrm{~g}(\mathrm{SD}=3.4)$ to $55.4 \mathrm{~g}(\mathrm{SD}=5.5)$, respectively (Holm-Šídák, $\mathrm{p}<0.001)$ and were significantly heavier than WT at both time points (Holm-Šídák, $\mathrm{p}<0.001)$. In contrast, there was not a statistically significant difference in weight for WT mice from week 10 ( $\mathrm{M}=18.9, \mathrm{SD}=1.6, \mathrm{~g})$ to 21 (M $234=20.0, \mathrm{SD}=1.2, \mathrm{~g})($ Figure 2A, Holm-Š́ídák, $\mathrm{p}=0.082)$. [Two way ANOVA: Genotype; F $(1,43)=$ 169.319, $\mathrm{p}<10^{-8}$. Age; $\mathrm{F}(1,43)=21.285, \mathrm{p}=3.5 \times 10^{-5}$. Interaction; $\left.\mathrm{F}(1,43)=3.401, \mathrm{p}=0.072\right]$. glucose (Figure 2B) significantly decreased from $352.54 \mathrm{mg} / \mathrm{dl}(\mathrm{SD}=115.22)$ at week 10 to $196.62 \mathrm{mg} / \mathrm{dl}$

$238(\mathrm{SD}=113.16)$ at week 21 , this phenomena has been reported for C57BL/6J mice before, however, usually at later time points ( week 25-30; although still elevated compared to control (Gunnarsson 1975).

240 Despite this, consistent with the diabetic phenotype, fasting blood glucose was significantly elevated in 241 diabetic mice for both week 10 (Holm-Š́́dák, $\mathrm{p}<0.001$ ) and week 21 (HS, p = 0.044) vs WT (Figure 2B). 242 In contrast to diabetic mice, no significant difference was observed in the fasting blood glucose of WT mice between weeks $10(\mathrm{mg} / \mathrm{dl}, \mathrm{M}=112.47, \mathrm{SD}=27.14)$ and $21(\mathrm{M}=107.17, \mathrm{SD}=8.72 ; \mathrm{Holm}-\mathrm{S}$ ídák, $\mathrm{p}$

$244=0.901)$. [2-way ANOVA: Genotype; $\mathrm{F}(1,43)=37.150, \mathrm{p}=2.7 \times 10^{-7}$. Age; $\mathrm{F}(1,43)=8.893, \mathrm{p}=$ 0.005. Interaction; $F(1,43)=7.762, \mathrm{p}=0.008]$. to increase (Gunnarsson 1975). Mean plasma insulin levels (Figure 2C) in diabetic mice were stable from week $10(\mathrm{ng} / \mathrm{ml}, \mathrm{M}=29.51, \mathrm{SD}=40.19)$ to week $21(\mathrm{ng} / \mathrm{ml}, \mathrm{M}=35.11, \mathrm{SD}=46.51 ;$ Holm-Š́íák, $\mathrm{p}=$ 0.908), but were significantly elevated compared to WT(Holm-Šídák, $\mathrm{p}<0.001)$ which also did not change from weeks $10(\mathrm{ng} / \mathrm{ml}, \mathrm{M}=0.51, \mathrm{SD}=0.43)$ to 21 (ng/ml, $\mathrm{M}=0.33, \mathrm{SD}=0.07$; Holm-Š́́dák, $\mathrm{p}=$ 
251 0.817). Together, these results support that the Lepr ${ }^{\mathrm{db} / \mathrm{db}}$ manifests the insulin resistant, type II diabetic

252 phenotype.

Firing properties of Lepr ${ }^{d b / d b}$ neurons changes with diabetic condition and time

DB10 and DB21 neurons have enhanced and reduced excitability, respectively. Our hypothesis

was that since diabetes causes diabetic cystopathy (Kebapci et al. 2007), presumably at least in part

through diabetic autonomic dysregulation (Nadelhaft and Vera 1992), Lepr ${ }^{\mathrm{db} / \mathrm{db}}$ efferent bladder-

innervating neurons of the MPG may contribute to these pathological changes and may manifest

themselves as changes in intrinsic excitability. Therefore, we first examined whether MPG neurons from

different diabetic conditions would spike differently in response to depolarizing current steps from 0 to

$+700 \mathrm{pA}$ in $50 \mathrm{pA}$ increments (Figure 3A). We used 114 cells from 10 -week-old WT mice $(\mathrm{WT}, \mathrm{n}=37)$;

5, 10-week-old diabetic mice (DB10, $\mathrm{n}=41)$ and 5, 21-week-old diabetic mice (DB21, $\mathrm{n}=36)$. As we

saw no difference in metabolic parameters for WT mice from weeks 10 to 21 (Figure 2), we assume WT

physiology is likewise similar to WT21. Thus all WT recordings are made from 10 -week old animals. The

representative neurons in Figure 3A show that DB10 (Red) neurons appear to be more excitable than WT

(Black). In contrast, DB21 neurons (Green) were less excitable than either DB10 or DB21, and appeared

272 respectively. Supporting this difference in excitability, a Chi square test showed that these groups were

273 not statistically independent $\left(X^{2}(2, N=114)=8.268, \mathrm{p}=0.016\right)$. Similarly; a Kruskal-Wallis showed this

274 data was significantly different, however, this test is more dubious as all groups had median $=1($ Table 1$)$.

275 Due to this low spike probability, we could not run more conventional IO curves. Therefore, instead of IO 
curves, we examined the cumulative probability of producing one or more spikes as a function of current

277

278

279

280

281

282

283

284

285

286

287

288

289

290

injected. A two way ANOVA for factors current and condition showed that cumulative probability of

firing 1 or more spikes as a function of injected current was reduced in DB21 condition [Condition; F (2, $1443)=37.997 \mathrm{p}<1 \times 10^{-8}$. Current $\mathrm{F}(12,1443)=51.817, \mathrm{p}<1 \times 10^{-8}$. Interaction; $\mathrm{F}(24,1443)=$ 2.038, $\mathrm{p}=0.002$. ]. The probability of a neuron firing at least once (Top, Figure 3C) was not significantly different between DB10 and WT neurons (Holm-Šídák, p = 0.883), in contrast, DB21 had reduced probability of firing at least one spike from current injections of 100 to $350 \mathrm{pA}$ when compared to DB10 (Holm-Šídák p < 0.05) and from 100 to 400 pA when compared to WT (Holm-Šídák p < 0.05).

Unfortunately, this particular distribution was neither normally distributed nor homoscedastic due to its binary nature. Supporting the reduced excitability of DB21 neurons was the finding that median rheobase (Left, Figure 3B) was increased in DB21 $(\mathrm{Mdn}=300 \mathrm{pA}, \mathrm{IQR}=450-200, \mathrm{pA})$ relative to $\mathrm{WT}(\mathrm{Mdn}=$ 175, IQR = 262.5-100, pA) (Dunn's test, p < 0.01) and DB10 (Mdn = 150, IQR = 250-100, pA) (Dunn's test, $\mathrm{p}<0.01)$ [Kruskal Wallis ANOVA on Ranks; $\mathrm{H}(2)=16.181, \mathrm{p}<0.001$ ]. Together, these data support DB21 mice having reduced MPG excitability.

DB10 condition enhances excitability. When examining the probability of these neurons firing twice or more, neurons from DB10 had significantly greater probability of firing more than two spikes compared to both WT and DB21 (Bottom, Figure 3C). This change was significant from current ranges 350-700 pA vs DB21 (Holm-Šídák, p < 0.05) and 400-700 pA vs WT (Holm-Šídák, p < 0.05) [Condition; F (2, 1443) $=43.428, \mathrm{p}<1 \times 10^{-8}$. Current; $\mathrm{F}(12,1443)=2.251, \mathrm{p}=0.008$. Interaction; $\mathrm{F}(24,1443)=1.301, \mathrm{p}=$ 0.150. ]. Median DB10 rheobase (Left, Figure 3B; Mdn 150, IQR = 250-100, pA) was not significantly different from WT (Mdn 150, IQR = 275-100, pA) (Dunn's, p > 0.05), but was significantly less compared to DB21 (Mdn 300, IQR = 450-200, pA) (Dunn's, p < 0.05) [Kruskal-Wallis, H (2) = 16.053, p $<0.001]$. In agreement with this, DB10 threshold (Center, Figure 3B; Mdn = -25.0, IQR = -20.5-(-30), $\mathrm{mV}$ ) was hyperpolarized compared to DB21 (Mdn = -19.5, IQR = -15-(-24), mV) (Dunn's test, $\mathrm{p}<0.01)$, 
301

302

303

304

305

306

307

308

309

310

311

312

however, it was not significantly different from WT (Mdn = -22.0, IQR = -18-(-27.5), mV) but [Kruskal Wallis ANOVA on Ranks; H $(2)=9.351, \mathrm{p}=0.009$ ]. These results, suggest that DB10 excitability is enhanced relative to WT and DB21 conditions.

Rebound spike latency is decreased in DB10 neurons. Another sign that excitability was increased in DB10 neurons was that latency to first spike after release of hyperpolarizing current injection (Right, Figure 3B) was significantly decreased in the DB10 condition (; $\mathrm{Mdn}=7.9, \mathrm{IQR}=13.9-7.1, \mathrm{~ms})$ compared to WT $(\mathrm{Mdn}=15.4, \mathrm{IQR}=20.9-11.5, \mathrm{~ms})(\mathrm{HS}, \mathrm{p}<0.05)$ and $\mathrm{DB} 21(\mathrm{Mdn}=15.7, \mathrm{IQR}=21.2-$ 14.1, ms) (Holm-Š́́dák, $\mathrm{p}<0.05)$ conditions. These data support excitability being enhanced in the DB10 condition.

\section{Passive properties of diabetic neurons change with age and diabetic condition}

In order to characterize the mechanism of observed changes in firing of MPG neurons, we first examined passive properties with the prediction that we should observe depolarized resting membrane potential (RMP) and reduced input resistance in diabetic neurons . In contrast to Tompkins et al. (2013), our data showed no difference in median resting membrane potential (Figure $4 \mathrm{~A})$ between WT $(\mathrm{Mdn}=-$ 43.0, IQR = -36.5-(-47.0), mV), DB10 $(\mathrm{Mdn}=-42.0, \mathrm{IQR}=-39.5-(-48.5), \mathrm{mV})$ or DB21 $(\mathrm{Mdn}=-40.0$, $\mathrm{IQR}=-38.0-(-45.5), \mathrm{mV})($ Figure 4A) [Kruskal-Wallace ANOVA on ranks; H $(2)=2.018, \mathrm{p}=0.365]$.

However, consistent with Tompkins et al.and our finding of rheobase being increased in DB21, we found that median input resistance (Figure 4B) was significantly reduced in DB21 ( $\mathrm{Mdn}=42.5$, IQR $=51.8$ 37.3, M $\Omega$ ) (Dunn's test; $\mathrm{p}<0.004)$ but not in DB10 (Mdn = 51.0, IQR = 89.0-38.0, M $\Omega$ ) (Dunn's test, $\mathrm{p}$ $>0.05)$ neurons vs $\mathrm{WT}(\mathrm{Mdn}=68, \mathrm{IQR}=89.0-44.0, \mathrm{M} \Omega)$ neurons [Kruskal-Wallis ANOVA on ranks, $\mathrm{H}$ $(2)=10.641, p=0.005]$. We next estimated time constant by a 2-exponential fit (Golowasch et al. 2009; White and Hooper 2013). Median time constant (Figure 4C) showed a similar pattern, showing a 
significant reduction in DB21 $(\mathrm{Mdn}=1.8, \mathrm{IQR}=2.5-1.5, \mathrm{~ms})$ compared to $\mathrm{WT}(\mathrm{Mdn}=2.3, \mathrm{IQR}=3.2-$ 1.6, ms) (Dunn's test, $\mathrm{p}<0.01)$, but not compared to DB10 ( $\mathrm{Mdn}=2.5, \mathrm{IQR}=4.2-1.7, \mathrm{~ms})$ (Dunn's test, $\mathrm{p}>0.05$ [Kruskal-Wallis one way ANOVA on ranks, $\mathrm{H}(2)=6.805, \mathrm{p}=0.033]$. Capacitance (Figure 4D) showed a different pattern, where both DB10 $(\mathrm{Mdn}=48.7, \mathrm{IQR}=57.8-39.6, \mathrm{pF})$ and DB21 $(\mathrm{Mdn}=41.9$, $\mathrm{IQR}=54.8-35.1, \mathrm{pF})$ were significantly increased relative to $\mathrm{WT}(\mathrm{Mdn}=32.9, \mathrm{IQR}=40.2-29.8, \mathrm{pF})$ (Dunn's test, $\mathrm{p}<0.01$ ) [[Kruskal-Wallis one way ANOVA on ranks, $\mathrm{H}(2)=23.187, \mathrm{p}<0.001]$. These data suggest that capacitance is increased with diabetic condition independent of time, while time constant and resistance change with diabetic condition and age.

Action potential properties in diabetic neurons change with age.

In order to establish how observed changes in excitability caused by diabetic condition occurred, we examined whether diabetic condition and age modulated properties of the action potentials shown in figure 1.

Ascending spike slope is increased in response to depolarizing current injection in the DB10 condition

but not first rebound spike. We looked at ascending action potential slope $\left(\frac{d v}{d t}\right)$ in response to depolarizing current injections (Figure 1,9). DB10 mice had significantly greater median ascending spike slope (Figure 5A, Mdn = 30.0, IQR = 52.5-9.5, mv/ms) compared to either $\mathrm{WT}(\mathrm{Mdn}=8, \mathrm{IQR}=19.0-3.3$, mv/ms) (Dunn's Test; $\mathrm{p}<0.01)$ or DB21 mice $(\mathrm{Mdn}=5$, IQR = 20.3-3.0, mv/ms) (Dunn's Test; $\mathrm{p}<0.01)$

343 [Kruskal-Wallis ANOVA on Ranks; $\mathrm{H}(2)=22.365, \mathrm{p}<0.001]$. Interestingly, in contrast to evoked 344 spikes, when we examined median maximum ascending slope (i.e. bins of $0.02 \mathrm{~ms}$; Figure 1, 10), in 345 rebound spikes, DB10 neurons (Figure 5C, Mdn =62.8, IQR = 77.9-40.3, $\mathrm{mv} / \mathrm{ms}$ ) did not significantly 346 differ from WT $(\mathrm{Mdn}=55.3, \mathrm{IQR}=77.9-40.3, \mathrm{mv} / \mathrm{ms})$ or DB21 $(\mathrm{Mdn}=40.3, \mathrm{IQR}=56.6-25.6$,

$347 \mathrm{mv} / \mathrm{ms}$ )[Kruskal-Wallis ANOVA on Ranks; $\mathrm{H}(2)=5.670, \mathrm{p}=0.059]$. We believe this difference was 348 real and not due to a reduction in statistical power, as within WT groups, the coefficient of variance in 
ascending slope for depolarizing current injections was greater $(\mathrm{CV}=1.14)$ than for rebound spikes $(\mathrm{CV}$ $=0.79)$. In support of there being no differences in rebound spikes, when ascending spike slope was quantified using a 10-90\% rise slope criterion (Figure 1,7), DB10 neurons (Figure 5G, Mdn = 29.8, IQR $=40.6-15.4, \mathrm{mv} / \mathrm{ms})$ did not significantly differ from either $\mathrm{WT}(\mathrm{Mdn}=25.8, \mathrm{IQR}=39.5-12.4, \mathrm{mv} / \mathrm{ms})$ or DB21 $(\mathrm{Mdn}=20.0, \mathrm{IQR}=32.7-11.5, \mathrm{mv} / \mathrm{ms})$ [Kruskal-Wallis ANOVA on Ranks; $\mathrm{H}(2)=2.043, \mathrm{p}=$ 0.360]. These data support spike slope increasing in the DB10 condition in response to depolarization driven spikes but not rebound spikes.

AP half-width is decreased while decay slope is increased in rebound spikes of DB10 neurons. In contrast 14.991, $\mathrm{p}<0.001]$.

Part of the reduction in DB10 half-width may be explained by the finding that that both maximal and $90-10 \%$ decay slope increased (Also see discussion). This is shown as median maximal decay slope

364 (Figure 5D) was made more negative (increased) in DB10 neurons ( $\mathrm{Mdn}=-20.0, \mathrm{IQR}=-14.7-(-24.6)$, $\mathrm{mv} / \mathrm{ms})$ vs DB21 neurons $(\mathrm{Mdn}=-13.4, \mathrm{IQR}=-9.7-(-18.9), \mathrm{mv} / \mathrm{ms})($ Dunn's test, $\mathrm{p}<0.05)$ but not vs WT $(\mathrm{Mdn}=-16.0, \mathrm{IQR}=-11.3-(-22.1), \mathrm{mv} / \mathrm{ms})$ (Dunn's test, $\mathrm{p}>0.05)$ neurons [Kruskal-Wallis ANOVA on Ranks; $\mathrm{H}(2)=8.112, \mathrm{p}=0.017$ ] suggesting these neurons repolarized faster. In agreement with this, mean 90-10\% decay slope (Figure 5H) also became more negative in the DB10 condition( $\mathrm{M}=-16.7$, SD $369=5.3, \mathrm{mv} / \mathrm{ms})$ vs WT $(\mathrm{M}=-12.4, \mathrm{SD}=5.6, \mathrm{mv} / \mathrm{ms})($ Holm Sidak, $\mathrm{p}=0.001)$ and compared to DB21 $(\mathrm{M}=$ $370-11.0, \mathrm{SD}=4.2, \mathrm{mv} / \mathrm{ms}), \mathrm{mv} / \mathrm{ms})($ Holm-Sidak, $\mathrm{p}<0.001)$ [One way ANOVA; F $(2,100)=11.541, \mathrm{p}=$ $3713.1 \times 10^{-5}$. Accordingly, median 90-10\% decay time (Figure 5F) significantly decreased in DB10 $(\mathrm{Mdn}=$ 372 2.7, IQR = 3.1-2.5, ms) vs WT $(\mathrm{Mdn}=3.7, \mathrm{IQR}=4.8-3.0, \mathrm{~ms})($ Dunn's test, $\mathrm{p}<0.01)$ and $\mathrm{DB} 21(\mathrm{Mdn}=$ 
0.001]. This data, in combination with the finding that AP ascending slope did not increase in rebound

375

376

spikes, suggests that AP half-width decreased primarily through a mechanism that increases AP

descending slope.

\section{$A P$ area and AHP decay constant decreased in DB10 with no changes in after hyperpolarization}

$(A H P)$ area. Consistent with decreased AP half-width, total AP area (excluding the AHP; Figure 5I) was significantly decreased in DB10 neurons $(\mathrm{Mdn}=174.4, \mathrm{IQR}=238.8-142.7, \mathrm{mV} \cdot \mathrm{ms}$ ) relative to $\mathrm{DB} 21$ $(\mathrm{Mdn}=232.5, \mathrm{IQR}=266.7-217.5, \mathrm{mV} \cdot \mathrm{ms})($ Dunn's test, $\mathrm{p}<0.05)$ but not when compared to WT $(\mathrm{Mdn}=$ 209.8, IQR $=290.7-172.0, \mathrm{mV} \cdot \mathrm{ms})($ Dunn's test, $\mathrm{p}>0.05)$ [Kruskal-Wallis ANOVA on Ranks; H $(2)=$ $12.320, \mathrm{p}=0.002]$. This was not due to changes in spike height, as neither DB10 $(\mathrm{Mdn}=63.6, \mathrm{IQR}=$ 78.1-37.9, $\mathrm{mV})$ nor DB21 $(\mathrm{Mdn}=61.2, \mathrm{IQR}=75.9-53.8, \mathrm{mV})$ differed significantly in spike height (Table 1) relative to $\mathrm{WT}(\mathrm{Mdn}=64.5, \mathrm{IQR}=80.1-52.7, \mathrm{mV})[$ Kruskal-Wallis ANOVA on Ranks; $\mathrm{H}(2)=$ $0.498, \mathrm{p}=0.779$ ]. If AP area decreased, a possible mechanism would be activation of outward currents, and one might expect to see an enhanced AHP. However, no change in AHP area (Figure 5J) for DB10 $(\mathrm{Mdn}=-141.6, \mathrm{IQR}=-88.1-(-259.2), \mathrm{mV} \cdot \mathrm{ms})$, nor DB21 $(\mathrm{Mdn}=-121.9, \mathrm{IQR}=-92.1-(200.5), \mathrm{mV} \cdot \mathrm{ms})$ vs WT $(\mathrm{Mdn}=116.6, \mathrm{IQR}=-80.6-(-251.1), \mathrm{mV} \cdot \mathrm{ms})$ was observed $[\mathrm{H}(2)=0.530, \mathrm{p}=0.767)]$. Neither were changes were observed in AHP height (figure 1, 2) in DB21 (Figure 5K, Mdn = -10.0, IQR = -5.8-(12.9), mv), DB10 (Mdn = -11.6, IQR = -7.7-(-15.4), mv) conditions vs WT (Mdn = -12.4, IQR = -8.5-(15.9), mv) [Kruskal-Wallis ANOVA on Ranks; H $(2)=2.900, p=0.235$ ]. Despite our finding of stable AHP amplitude and area, we did see that AHP decay tau significantly decreased in DB10 neurons $($ Mdn $=$ 13.0, IQR $=16.5-10.5, \mathrm{~ms})$ vs WT $(\mathrm{Mdn}=16.9, \mathrm{IQR}=21.2-16.9, \mathrm{~ms})($ Dunn's, $\mathrm{p}<0.01)$ and DB2 1 $(\mathrm{Mdn}=17.0, \mathrm{IQR}=20.0-13.4, \mathrm{~ms})($ Dunn's, $\mathrm{p}<0.05)($ Figure 5L) [Kruskal-Wallis ANOVA on ranks; H $(2)=11.896, p=0.003)]$. These data suggest that diabetic condition and age affect interact to alter AP area and AHP decay constant while leaving other AP parameters unmodified. $2^{\text {nd }}$ AHPs and ADPs after $145 \mathrm{~ms}$. When quantifying properties of the AHP, it was found that after the initial AHP, some neurons had after depolarizations, while some had secondary slower AHPs 
and still others had both. We attempted to systematically quantify this across conditions by analyzing the change in voltage $145 \mathrm{~ms}$ after the descending stroke of the AP recrossed baseline. However, this comes with the caveat that some neurons could not be quantified due to no change in baseline, multiple rebound spikes, or loss of cells. Within $73.0 \%$ (27/37) of quantified WT neurons, 81.5\% (22/27) displayed afterdepolarizations, while the remaining $18.5 \%$ (5/27) displayed secondary after hyperpolarizations and none displayed both. Within DB10 neurons 4.9\% (2/41) could not be classified due to multiple rebound spikes. However, of the $82.9 \%$ (34/41) that could be quantified, $44.1 \%(15 / 34)$ showed ADPs, $20.6 \%$

406 (7/34) showed secondary AHPs; in contrast to WT; where 29.4\% (10/34) of these neurons showed both 407 AHPs and ADPs. Within 94.4\% (34/36) of quantified DB21 neurons, 76.5\% (26/34) showed ADPs, 2.9\% 408 (1/34) showed secondary AHPs, while 20.6\% (7/34) showed both. A Chi Square test showed that these groups were statistically independent $\left(X^{2}(4, \mathrm{~N}=95)=15.960, \mathrm{p}=0.003\right)$. Alternatively, when we just quantified the absolute voltage change at $145 \mathrm{~ms}, \mathrm{DB} 10(\mathrm{Mdn}=-0.2, \mathrm{IQR}=2.0-(-0.7), \Delta \mathrm{mV})(\mathrm{Dunn}$ 's, $\mathrm{p}$ $<0.05$ ) but not DB21 (Mdn $=0.8, \mathrm{IQR}=1.8-0.9, \Delta \mathrm{mV})$ (Dunn's, $\mathrm{p}>0.05$ ) was significantly different from WT $(\mathrm{Mdn}=1.8, \mathrm{IQR}=3.8-0.9, \Delta \mathrm{mV})($ Table 1$)$ [Kruskal-Wallis ANOVA on Ranks; $\mathrm{H}(2)=$ of ADPs relative to WT.

$421 K C N M A)$. Of 30 ion channel genes studied, 8 were significantly different between DB10 and control

422 wild-type animals (Figure 6). The voltage-dependent $\mathrm{Ca}^{2+}$ channels CACNA1A, CACNA1E and 
was changed was a significant increase in $S C N 2 A 1$ in DB10 animals. In addition, $4 \mathrm{~K}^{+}$channel genes showed altered expression in DB10 animals: KCNA3 was significantly lower in DB10 animals, while $K C N B 1, K C N C 2$, and $K C N D 3$ were significantly higher in DB10 mice.

In DB21 animals, 12 channel genes showed differential expression relative to wild-type controls

428 (Figure 6). CACNA1D and CACNA1G were significantly higher in DB21 animals relative to control.

429 There were no significant differences in sodium channel gene expression seen between DB21 and wild-

430 type animals. However, there were 10 different $\mathrm{K}^{+}$channel genes that showed changes in expression in DB21 animals. $K C N A 2, K C N A 3, K C N A 5$, and $K C N C 3$ all were significantly lower in DB21 animals than wild-type, with $K C N A 2$ and $K C N C 3$ expression all but abolished in the DB21 animals. $K C N C 4, K C N D 2$, $K C N D 3, K C N N 1, K C N N 3$ and $K C N M A 1$ were all significantly higher in DB21, with $K C N D 2$ expression including KCNA2, KCNA5 KCNC3, KCNC4, KCND2, KCNN1, KCNN3 and KCNMA1.

Some changes seen in DB10 animals resolve to control levels in the DB21 animals, while others 437 persist throughout the DB21 time point (Figure 6). KCNA3 is significantly lower in DB10 animals, and 438 this change persists into the DB21 group. KCND3 is significantly increased in both DB10 and DB21 439 animals. Conversely, $K C N B 1$ is significantly higher in the DB10 animals, but returns to control levels in 440 DB21 animals. Finally, there are some channels that are significantly different only between DB10 and 441 DB21. KCNA1 and KCND1 are significantly higher in DB21 than DB10, although there is a trend 442 towards these two channels being downregulated in DB10 overall, even though this does not reach 443 statistical significance relative to control. The converse is true for $K C N B 2$, which is significantly higher in 444 DB10 than DB21 - although there is a trend for this channel to be transiently upregulated in the DB10 445 group. 


\section{Channel Expression}

We next used principal component analysis (PCA) to visualize potential patterns and correlations in the features that may underlie distinctions in both the spike properties and channel expression across groups. A variance plot of the first two principal components (PC) for spike characteristics (Figure 7A) demonstrates that there is overlapping features in all three groups that do not distinguish these groups in any obvious way. There is one major PC (PC1) that accounts for the majority of the variance in the data $42.5 \%$, Figure 7B). The variables that most contribute to the variance in spike characteristics largely consist of features involved in shaping the action potential dynamics underlying spike shape, such as decay slope, rise slope, and the amplitude of the spike (e.g. spike height, peak amplitude). These would consistent with changes in $\mathrm{Na}^{+}$and $\mathrm{K}^{+}$channel expression, particularly those subtypes involved in the spiking itself. However, there is no combination of features that separates the diabetic animals from the wild-types, or each other, in a discrete fashion.

The PCA for channel expression in the MPG tells a different story. The variance plot of PC1 and PC2 (Figure 8A) shows clear separation of all three groups, and the scree plot (Figure 8B) notes that these 462 two PCs account for the majority of the variance in the data. When looking at the channels that contribute 463 to PC1 and PC2, it is also clear validation of the changes in expression reported in Figure 6. By 464 examining the vector plot in Figure 8A and the contributions to PC1 in Figure 8B, it is possible to 465 discriminate a group of channels largely responsible for distinguishing the DB21 animals. The top ten 466 contributors to PC1 consists entirely of channels that are uniquely differentially expressed in DB21 467 animals relative to both DB10 and control. Conversely, by examining the top ten contributors to PC2 - in conjunction with the vector plot - it can be seen that PC2 consists of channels uniquely differentially 


\section{DISCUSSION}

473 Diabetic cystopathy has formally been documented since 1864 (Faerman et al. 1971), yet the only direct

474 attempt to document how diabetes impacts efferent bladder innervating neurons was by Tompkins et al.,

475 (2013) who focused largely on synaptic properties. Therefore, in this study we attempted to identify for

476 the first time the impacts of a type II diabetes model on the intrinsic properties of bladder-innervating

477 parasympathetic neurons in female mice. We hypothesized that passive properties, overall excitability and

478 action potential properties in MPG neurons would change in an age-dependent manner within the diabetic

479 condition. Furthermore, we examined underlying changes in mRNA levels for voltage-dependent ion

480 channels in the whole ganglion as a reflection of the most salient of changes in excitability and firing of

481 MPG neurons.

Lepr $^{\mathrm{db} / \mathrm{db}}$ mice on the C57B16/J strain used here model hyperglycemia and persistent

483 hyperinsulinemia with beta cell hypertrophy, whereas those on the BKS background strain progress to

484 beta cell failure (Hummel et al. 1972). Although the mice in this study were diabetic at both ages, their

485 hyperglycemia was somewhat worse at 11 weeks than at 21 weeks, consistent with previous observations

486 in this strain (Breyer et al. 2005; Sullivan et al. 2007). This improvement was consistent with the

487 constant, or slightly increasing serum insulin concentrations at 21 weeks, indicating that while the beta

488 cells are not able to adequately compensate for insulin resistance, they have not undergone beta cell

489 failure.

Diabetes interacts with time to first increase then decrease MPG neuron excitability

492 One of our most important findings was that excitability of MPG neurons in Lepr ${ }^{\mathrm{db} / \mathrm{db}}$ females changes

493 nonlinearly with the amount of time exposed to the diabetic environment. Specifically, we observed that

49410 week Lepr ${ }^{\mathrm{db} / \mathrm{db}}$ mice had an increased probability of firing two or more spikes, and decreased rebound

495 spike latency; both of which are measures of increased overall neuronal excitability. In contrast, week 21 
496 Lepr $^{\mathrm{db} / \mathrm{db}}$ neurons changed in the opposite direction, exhibiting a decrease in spike probability and

497 increased rheobase, both of which are indications of lower overall excitability. This trend of a change in

498 firing properties at 10 weeks that is then rectified at 21 weeks is also seen in the characteristics of action

499 potentials of MPG neurons. Specifically, spikes are narrower (as seen by a decreased half-width,

500 increased ascending slope and enhanced decay slope, and decreased decay time in DB10 animals), and

501 AHPs are shorter are in the DB10 animals but return to control levels in the DB21 group. These data are

502 consistent with the hypothesis that long-term diabetes results in change in MPG neuron that potentially

503 are compensated for via long-term plasticity mechanisms in the DB21 animals. Regardless of whether the

504 changes in excitability and action potential properties are compensatory or represent disease progression

505 in the context of the entire LUT, there is clear change in the characteristics of MPG neurons over the

506 course of 10-21 weeks in diabetic animals.

Because normal bladder function and diabetic cystopathy are the result of a complex interaction

508 of the activities of sympathetic, parasympathetic, and sensory feedback mechanisms combined with

509 bladder compliance and detrusor properties, it is not possible to interpret our results directly in context of

510 mechanisms of changes in bladder output as a result of diabetes. However, the time course of changes in

511 MPG neuron excitability mirror those of bladder output over the progression of diabetic cystopathy in

512 rodents. For example, in type I diabetic mice there is a sharp decline in basal bladder pressure and mean

513 threshold pressure from weeks 9-12 that then is rectified to control levels by 20 weeks (Daneshgari et al.

514 2006a). Similar time course changes in bladder output features as measured by cystometrogram have been

515 documented in rats as well, whereby diabetic bladders transition from compensated to decompensated

516 states between 9-12 weeks following onset of diabetes (Daneshgari et al. 2006b). Therefore, while a direct

517 mechanistic link to bladder output cannot be made from our data, the results are consistent with the

518 overall change in LUT output over the time course of diabetic cystopathy. 
It would be an over-interpretation to directly infer mechanisms underlying physiological changes

522 in single neurons from data collected at the mRNA level from whole ganglia. However, the steady-state

523 mRNA levels for ion channels provide a high-throughput opportunity to generate hypothesis regarding

524 underlying mechanistic changes in ionic currents. Indeed, we see multiple changes in channel mRNAs

525 that are consistent with the physiological changes we report. In this section, we will highlight some of the

526 most salient changes we found at the level of neuronal properties, and cautiously hypothesize on potential

527 underlying mechanism via changes at the mRNA level.

In 10-week Lepr ${ }^{\mathrm{db} / \mathrm{db}}$ mice we observed that although rheobase did not change, several properties associated with excitability did change. The most salient of these properties was the increase of the probability of firing 2 or more spikes. As shown in Figure 3A and also previously documented (Suzuki and Rogawski 1989; Tompkins et al. 2013), MPG neurons can spike once or many times, a phenomena observed in many other autonomic neuron types (Cassell et al. 1986; Malin and Nerbonne 2001; Springer et al. 2015). One obvious possible mechanism for generating multiple spikes is the activation of a

534 depolarizing current with somewhat slower kinetics that can maintain depolarization above threshold to 535 allow for the generation of multiple spikes. Our data show changes in channel expression that are 536 consistent with this hypothesis. In particular, there is a significant increase in mRNA levels for the 537 calcium channels CACNA1A, CACNAIE, and CACNA1H in DB10 animals relative to both WT and 538 DB21. Furthermore, CACNA1E levels overall are the most abundant calcium channel mRNA that we 539 detected, with levels an order of magnitude higher than any other calcium channel subunit. CACNAIE 540 encodes the R-type current $\mathrm{Ca}_{\mathrm{v}} 2.3$, which is known to make up 25\% of total calcium current in rat MPG 541 neurons (Won et al. 2006), and $\mathrm{Ca}_{\mathrm{v}} 3.2$ - encoded by $C A C N A 1 H$ - is the predominant T-type channel in rat MPG (Lee et al. 2002). R-type currents are known to influence bursting output in CA1 pyramidal 543 neurons (Metz et al. 2005), and T-type currents in many neurons trigger low-threshold spikes, which in 544 turn generate bursts of action potentials (Perez-Reyes 2003). While the interplay of multiple calcium 545 channel subunits and the remaining ionic conductances of the cell are quite complex in terms of 
generating different output patterns, increases in R-type and T-type currents would be a feasible way to

547 influence the multiple spiking phenotype in DB10 animals.

We also observed increased ascending and descending spike slopes, and decreased spike halfwidth in the DB10 animals relative to WT and DB21. We observed increased expression of mRNAs coding for $\mathrm{Na}_{\mathrm{v}} 1.2(S C N 2 A 1)$, as well as a trend for increased $\mathrm{Na}_{\mathrm{v}} \beta 1$ (SCN1B) expression, in the DB10 animals. $\mathrm{Na}_{\mathrm{v}} 1.2$ channels are largely localized to the axons and initial segments of unmyelinated neurons (Vacher et al. 2008), which is consistent with the post-ganglionic fibers of the MPG. $\mathrm{Na}_{\mathrm{v}} \beta 1$ is known to interact with $\mathrm{Na}_{\mathrm{v}} 1.2$ channels to increase surface expression of these subunits (Isom et al. 1995).

Therefore, increases in expression of $S C N 2 A 1$ and $S C N B 1$ would be expected to increase AP upstroke, which was observed for depolarizing current injections but not rebound spikes. In addition, $\mathrm{K}_{\mathrm{v}} 3.2$ and $\mathrm{K}_{\mathrm{v}} 2.1$ are potassium channels with relatively high threshold activation and fast deactivation such that they have both been implicated as large contributors to the AP repolarization and as a consequence decrease AP width (Rudy and McBain 2001; Liu and Bean 2014). The upregulation of their constituent mRNA subunits (KCNC2 and $K C N B 1$ respectively) is entirely consistent with the firing phenotypes observed.

As we observed increases in ascending spike slope to depolarizing current injections, but not rebound current injections in DB10 neurons, it is possible that high threshold potassium currents with fast deactivation time constants could play a role in permitting multiple spikes during depolarizing current injections by enhancing sodium channel de-inactivation. As $\mathrm{K}_{\mathrm{v}} 2$ family members are known to encode delayed rectifiers, and $\mathrm{K}_{\mathrm{v}} 3$ channels have fast activation and deactivation rates associated with sustained higher-frequency firing, then the fact that we see increased $\mathrm{Kv} 3.2(K C N C 2)$ and $\mathrm{K}_{\mathrm{v}} 2.1(K C N B 1)$ expression is also consistent with these results. While this is well documented for $\mathrm{K}_{\mathrm{v}} 3.2$ as it is a high threshold, fast deactivating (Weiser et al. 1994; Rudy and McBain 2001) ion channel, it is less clear that this is the case for $K_{v} 2.1$ as it is intermediate in these parameters. For example, in the superior cervical ganglion ( $\mathrm{SCG}$ ) neurons, $\mathrm{K}_{\mathrm{v}} 2.1$ has somewhat high $\mathrm{V}_{1 / 2}$ activation, slow activation, slow or no inactivation, but a relatively fast deactivation (Liu and Bean 2014). If $\mathrm{K}_{\mathrm{v}} 2.1$ is playing a role in keeping 
571 the functional pool of sodium channels available through de-inactivation, as it is thought to do in SCG

572 neurons (Liu and Bean 2014), then we expect its upregulation should prevent decay in spike height during

573 a train of spikes. Therefore, to test this prediction, we examined the ratio of the $2^{\text {nd }}$ to $1^{\text {st }}$ spike height of

574 multi-spiking neurons. A t-test showed that $2^{\text {nd }}$ to $1^{\text {st }}$ spike ratio of DB10 neurons $(0.79 \pm 0.03, \mathrm{n}=8)$

575 were significantly less attenuated than WT neurons $(0.48 \pm 0.11, \mathrm{n}=2)(\mathrm{t}(8)=-4.416, \mathrm{p}=0.002)$. This

576 suggests that together $\mathrm{K}_{\mathrm{v}} 3.2$ and $\mathrm{K}_{\mathrm{v}} 2.1$ could play a role in keeping sodium currents de-inactivated in the

577 DB10 condition.

DB21 neurons were significantly less excitable than both DB10 and wild type neurons: rheobase was significantly increased, and input resistance was significantly reduced compared to wildtype, and DB21 neurons did not produce a multi-spiking output when stimulated. DB21 neurons had significantly upregulated mRNAs encoding several low threshold slow deactivating potassium currents that would be expected to reduce excitability. The upregulation of $K C N A 1\left(\mathrm{~K}_{\mathrm{v}} 1.1\right)$ likely contributes to reduced excitability given a relatively low threshold of activation $(\sim-32 \mathrm{mV})$ and intermediate deactivation time constant (Grissmer et al. 1994). The upregulation of $K C N D 2\left(\mathrm{~K}_{\mathrm{v}} 4.2\right)$ is consistent with the observed decrease in excitability and may explain in part why the DB21 condition did not share the multispiking phenotype with DB10. This is because in cultured rat superior cervical ganglion neurons, Malin and

587 Nerbonne (2000) showed that when $\mathrm{K}_{\mathrm{v}} 4.2$ is overexpressed, the number of neurons displaying the multi-

588 spiking neuron phenotype is decreased, and when the gene is downregulated by expression of a dominant 589 negative transgene, there is a corresponding increase in the multi-spiking phenotype. Interestingly, the 590 authors also report increased input resistance in cells with reduced $\mathrm{K}_{\mathrm{v}} 4.2$, and decreased input resistance 591 with overexpression of $\mathrm{K}_{\mathrm{v}} 4.2$ (Malin and Nerbonne 2001) which is consistent with the significant 592 decrease in $\mathrm{R}_{\text {in }}$ in DB21 neurons. 


\section{Conclusions}

We expected excitability of Lepr ${ }^{\mathrm{db} / \mathrm{db}}$ neurons to change with increasing intensity from weeks 10

597 to 21 as diabetes progressed as diabetic neuropathy is a function of both hyperglycemia and duration in

598 humans (Maser et al. 1989; Davies et al. 2006), rats (Mattingly and Fischer 1983; Sasaki et al. 2002) and

599 mice (Giachetti 1978; Hinder et al. 2017; Liu et al. 2017). Contrary to this hypothesis, many properties

600 associated with excitability changed in 10-week animals, but were then resolved closer to wild-type levels

601 in the 21-week animals. These properties include both characteristics of intrinsic excitability (e.g.

602 probability to fire, threshold, and rebound latency) as well as many of the characteristics of the individual

603 action potentials of these neurons as well. Yet, our expression profiling of the MPGs does not simply

604 reveal a resolution at 21-weeks of changes in expression that occur in the 10-week animals. Rather, our

605 PCA reveals that the overall expression patterns in MPGs of wild type, 10-week, and 21-week animals are

606 entirely distinct. Taken together, we suggest that these results represent an apparent compensatory

607 response, where neurons of the MPG in younger diabetic mice are less adapted to hyperglycemia, or the

608 associated bladder cystopathy, than older diabetic mice that have been exposed to hyperinsulinemia for

609 longer times.

610

611 


\section{TABLES}

Table 1. Non-parametric (non-normal or non-homoscedastic) negative or redundant statistical summary $\dagger$ Internal control that is best fit line to sampled interval. $\$ \mathrm{n}$ was $27,32,34$ for WT, DB10 and DB21 respectively.

\begin{tabular}{|c|c|c|c|c|c|c|c|c|c|c|}
\hline & \multicolumn{3}{|c|}{$\begin{array}{c}\text { WT } \\
\mathrm{n}=35\end{array}$} & \multicolumn{3}{|c|}{$\begin{array}{l}\text { DB10 } \\
\mathrm{n}=34\end{array}$} & \multicolumn{3}{|c|}{$\begin{array}{l}\text { DB21 } \\
\mathrm{n}=34\end{array}$} & \multirow{2}{*}{$\begin{array}{c}\text { Kruskal- } \\
\text { Wallis } \\
\mathrm{p}=\end{array}$} \\
\hline Property (units) & Mdn. & $\begin{array}{l}75^{\text {th }} \\
\text { per. }\end{array}$ & $\begin{array}{l}25^{\text {th }} \\
\text { per. }\end{array}$ & Mdn. & $\begin{array}{l}75^{\text {th }} \\
\text { per. }\end{array}$ & $\begin{array}{l}25^{\text {th }} \\
\text { per. }\end{array}$ & Mdn. & $\begin{array}{l}75^{\text {th }} \\
\text { per. }\end{array}$ & $\begin{array}{l}25^{\text {th }} \\
\text { per. }\end{array}$ & \\
\hline $\begin{array}{l}1^{\text {st }} \text { spike latency at } \\
\text { depolarizing rheobase } \\
(\mathrm{ms})\end{array}$ & 14.2 & 17.7 & 10.8 & 13.9 & 17.6 & 12.2 & 15.3 & 18.3 & 11.7 & 0.793 \\
\hline $\begin{array}{l}1^{\text {st }} \text { spike latency for } \\
\text { Rebound spikes }(-500 \\
\text { pA) }\end{array}$ & 15.2 & 22.3 & 11.6 & 7.9 & 13.9 & 7.9 & 15.7 & 21.2 & 14.1 & $<0.001$ \\
\hline $\begin{array}{l}\text { Baseline slope } \\
(\mathrm{mV} / \mathrm{ms})^{\dagger}\end{array}$ & -0.3 & -0.2 & -0.5 & -0.3 & -0.1 & -0.4 & -0.2 & -0.1 & -0.4 & 0.424 \\
\hline $\begin{array}{l}\text { Time from spike peak } \\
\text { to AHP peak }(\mathrm{ms})\end{array}$ & 8.3 & 11 & 7.3 & 6.9 & 7.5 & 6.1 & 9.8 & 11.2 & 8.1 & $<0.001$ \\
\hline Spike Height $(\mathrm{mV})$ & 64.5 & 80.1 & 52.7 & 63.6 & 78.1 & 37.9 & 61.2 & 75.9 & 53.8 & 0.779 \\
\hline Max Spikes (spikes) & 1.0 & 1.0 & 1.0 & 1.0 & 1.5 & 1.0 & 1.0 & 1.0 & 1.0 & 0.004 \\
\hline $\begin{array}{l}\text { Rebound spikes (-500 } \\
\text { pA; spikes) }\end{array}$ & 1.0 & 1.0 & 1.0 & 1.0 & 1.0 & 1.0 & 1.0 & 1.0 & 1.0 & 0.628 \\
\hline $\begin{array}{l}\text { Change in Membrane } \\
\text { potential } 145 \text { ms after } \\
\text { AP repolarization } \\
(\mathrm{mV}) \ddagger\end{array}$ & 1.8 & 3.8 & 0.9 & -0.2 & 2.0 & -0.7 & 0.8 & 1.8 & 0.2 & 0.005 \\
\hline
\end{tabular}

614

615

616
Table 2. Negative or redundant statistical summary that was normal and homoscedastic. $\dagger$ Internal control that is essentially the RMP right after rebound. ${ }^{\ddagger}$ Redundant with area $\left(\frac{1}{T} \int_{t_{0}}^{t_{0}+T}\right.$ Area $)$

\begin{tabular}{|c|c|c|c|c|}
\hline & WT & DB10 & DB21 & One- way \\
\hline Property (units) & $\begin{array}{c}\text { Mean (SD) } \\
\mathrm{n}=35\end{array}$ & $\begin{array}{c}\text { Mean }(\mathrm{SD}) \\
\mathrm{n}=34\end{array}$ & $\begin{array}{c}\text { Mean }(\mathrm{SD}) \\
\mathrm{n}=34\end{array}$ & $\begin{array}{c}\text { ANOVA } \\
p=\end{array}$ \\
\hline AP Mean Height, $(\mathrm{mV}) \ddagger$ & $1.8(2.5)$ & $0.7(1.7)$ & $1.7(1.6)$ & 0.045 \\
\hline Baseline $(\mathrm{mV})^{\dagger}$ & $-41.0(7.8)$ & $-41(7.6)$ & $-38.8(5.9)$ & 0.378 \\
\hline
\end{tabular}




\section{FIGURE LEGENDS}

619

Figure 1. Action potential properties measured from depolarization and rebound induced spikes.

Each number corresponds to a given measurement, as described in the Methods. These numbers are referred to in the Results section when relevant. times; week 10 (left) or week 21 (right) in either wildtype (white) or diabetic conditions (red and green for weeks 10 and week 21 respectively). A. A two-way ANOVA for factors genotype and age showed that mouse weight was influenced by genotype and age. [Genotype; $F(1,43)=169.319, \mathrm{p}<10^{-8}$. Age; F $(1,43)=21.285, p=3.5 \times 10^{-5}$. Interaction; $\left.F(1,43)=3.401, p=0.072\right]$ B. A two-way ANOVA for factors genotype and age showed that fasting blood glucose was influenced by genotype and age.

629 [Genotype; $\mathrm{F}(1,43)=37.150, \mathrm{p}=2.7 \times 10^{-7}$. Age; $\mathrm{F}(1,43)=8.893, \mathrm{p}=0.005$. Interaction; $\mathrm{F}(1,43)=$ $6307.762, p=0.008]$. C. Two-way ANOVA for factors genotype and age showed that fasting serum insulin was influenced by genotype. [Genotype; $\mathrm{F}(1,43)=71.608, \mathrm{p}<10^{-8}$. Age; $\mathrm{F}(1,43)=0.0595, \mathrm{p}=0.809$. Interaction; $\mathrm{F}(1,43)=0.0113, \mathrm{p}=0.916$ ]. Holm-Sidak Post-Hoc test; $*, \mathrm{p}<0.05 ; * *, \mathrm{p}<0.01$. Error bars are SEM.

Figure 3. DB10 and DB21 conditions increase and decrease excitability of MPG neurons, ANOVA on ranks showed that diabetic condition significantly altered latency to rebound spike $[\mathrm{H}(2)=$ 22.897, $\mathrm{p}<0.001$ ]. Shown are Medians, quartiles and outliers. Dunn's test; ${ }^{*}, \mathrm{p}<0.05 ; * *, \mathrm{p}<0.01 . *^{* *}$, 
643 probability of firing 1 or more spikes as a function of injected current was reduced in DB21 condition

$644 \quad\left[\right.$ Condition; $\mathrm{F}(2,1443)=37.997 \mathrm{p}<1 \times 10^{-8}$. Current; $\mathrm{F}(12,1443)=51.817, \mathrm{p}<1 \times 10^{-8}$. Interaction; $\mathrm{F}$

$645(24,1443)=2.038, \mathrm{p}=0.002$. ]. Bottom: A two-way ANOVA showed that the Cumulative probability of

646 firing 2 or more spikes as a function of injected current was increased in the DB10 condition [Condition;

$647 \mathrm{~F}(2,1443)=43.428, \mathrm{p}<1 \times 10^{-8}$. Current; $\mathrm{F}(12,1443)=2.251, \mathrm{p}=0.008$. Interaction; $\mathrm{F}(24,1443)=$

648 1.301, $\mathrm{p}=0.150$. ]. Note difference in scale. Holm-Sidak post hoc tests: $\mathrm{p}<0.05 ; *$ WT10 vs DB10, $\dagger$

649 WT10 vs DB21, DB10 vs DB21. Shown are Means \pm SEM.

650

651

652

653

654

655

656

657

658

659

660

661

662

663

664

665

666

667

Figure 4. Effect of condition for WT, DB10, and DB21 condition on passive properties of MPG neurons.

A. A Kruskal-Wallis one-way ANOVA on ranks showed that diabetic condition did not affect resting membrane potential $(\mathrm{RMP})[\mathrm{H}(2)=2.017, \mathrm{p}=0.365]$. B. A Kruskal-Wallis one-way ANOVA on ranks

showed that diabetic condition altered input resistance $\left(R_{\text {in }}\right)[H(2)=10.641, p=0.005]$ C. A KruskalWallis one way ANOVA on ranks showed that diabetic condition altered membrane time constant [H (2) $=6.805, p=0.033]$ D. A Kruskal-Wallis one-way ANOVA on ranks showed that diabetic condition altered capacitance of MPG neurons $[\mathrm{H}(2)=23.187, \mathrm{p}<0.001]$. Data shown are medians, quartiles and outliers. Dunn's test: * $\mathrm{p}<0.05 ; * *, \mathrm{p}<0.01$.

Figure 5. Action potential (AP) parameters are altered by DB condition in mouse MPG neurons. AP properties illustrated in figure 1 were quantified in 10 week wildtype (Black), 10 week Diabetic (Red) and 21 week diabetic (Green) in mouse MPG neurons. All data except A were quantified from rebound spikes. A. A Kruskal-Wallis one way ANOVA on ranks showed that diabetic condition affected ascending spike slope elicited by depolarizing current injection (Figure 1,9) during depolarizing current injection of MPG neurons [H (2) =22.010, $\mathrm{p}<0.001]$. B. A Kruskal-Wallis one way ANOVA on ranks showed that diabetic condition affected AP half-width (Figure 1, 3) $[\mathrm{H}(2)=14.892, \mathrm{p}<0.001]$. C. A Kruskal-Wallis one way ANOVA on ranks showed that diabetic condition did not significantly alter AP maximum rise slope (Figure 1,10$)[\mathrm{H}(2)=5.670, \mathrm{p}=0.059]$. D. A Kruskal-Wallis one way ANOVA on ranks showed that diabetic condition altered maximum AP decay slope of (Figure 1, 11) [H (2) = 8.112, p 
$668=0.017]$. E. A Kruskal-Wallis one way ANOVA on ranks showed that diabetic condition altered AP 10-

$66990 \%$ rise time (Figure 1,4$)[\mathrm{H}(2)=6.464, \mathrm{p}=0.039]$. F. A Kruskal-Wallis one way ANOVA on ranks

670 showed that diabetic condition altered 90-10\% decay time (Figure 1, 5) $[\mathrm{H}(2)=42.223, \mathrm{p}<0.001]$. G. A

671 Kruskal-Wallis one way ANOVA on ranks showed that diabetic condition did not alter AP 10-90\% rise

672 slope (Figure 1,7$)[\mathrm{H}(2)=2.043, \mathrm{p}=0.360]$. H. A one-way ANOVA showed that diabetic condition

673 altered $90-10 \%$ decay slope (Figure 1,8$)\left[\mathrm{F}(2,101)=11.541, \mathrm{p}=3.1 \times 10^{-5}\right]$. I. A Kruskal-Wallis one-

674 way ANOVA on ranks showed that diabetic condition altered AP area (Figure 1, 6) $[\mathrm{H}(2)=12.320, \mathrm{p}=$

675 0.002]. J. A Kruskal-Wallis one-way ANOVA on ranks showed that diabetic condition did not alter AHP

676 area $($ Figure 1,13$)[\mathrm{H}(2)=0.530, \mathrm{p}=0.767)]$. K. A Kruskal-Wallis one-way ANOVA on ranks showed

677 that diabetic condition did not alter AHP amplitude (Figure 1, 2) $[\mathrm{H}(2)=2.900, \mathrm{p}=0.235)]$. L. A

678 Kruskal-Wallis one way ANOVA on ranks showed that diabetic condition altered AHP decay tau (Figure

$6791,14)[\mathrm{H}(2)=11.896, \mathrm{p}=0.003)]$. Data shown are medians, quartiles and outliers. Dunn's test: * $\mathrm{p}<$

$680 \quad 0.05 ; * *, \mathrm{p}<0.01$

Figure 6. mRNA copy numbers for ion channel subunits of across WT, DB10, and DB21

experimental groups. Significant differences as noted ( $p<0.05$; post-hoc Holm-Š́ídák analyses

following One-Way ANOVA) represent pairwise comparisons across all three groups. Data shown are medians, quartiles and each individual value from a given animal.

Figure 7. Principal components analysis (PCA) of spike characteristic across WT, DB10, and DB21

mice. A. The first two principal components (PC1 and PC2) define the x-and y-axes respectively. PC1 accounted for $42.5 \%$ of the variance while PC2 accounted for $14.6 \%$. By and large, all three groups show overlapping distribution of variance across PC1 and PC2. B. Scree plot demonstrating the amount of variance accounted for across the first 10 principal components. A substantial plurality of the variance is accounted for in the first principal component, while the remainder contribute far less to the variance in 
693 Figure 8. PCA of ion channel mRNA levels across WT, DB10, and DB21 mice. A. The first two

694 principal components (PC1 and PC2) define the x-and y-axes respectively. PC1 accounted for $25.6 \%$ of

695 the variance while PC2 accounted for 21.9\%. The distribution across PC1 and PC2 reveals three distinct

696 ion channel expression profiles for WT, DB10, and DB21 animals. B. Scree plot demonstrating the

697 amount of variance accounted for across the first 10 principal components. The majority of the variance is

698 accounted for in the PC1 and PC2, while the remainder contribute far less to the variance in the data. C.

699 Post-hoc analysis of the variables that contribute to the variance in PC1 and PC2 reveals distinct channel

700 subunits that account for the distinct patterns of expression seen in all three experimental groups. 


\section{REFERENCES}

Breyer MD, Bottinger E, Brosius 3rd FC, Coffman TM, Harris RC, Heilig CW, Sharma K, Amdcc. Mouse models of diabetic nephropathy. J Am Soc Nephrol 16: 27-45, 2005.

Cassell JF, Clark AL, McLachlan EM. Characteristics of phasic and tonic sympathetic ganglion cells of the guinea-pig [Online]. J Physiol 372: 457-483, 1986. http://www.ncbi.nlm.nih.gov/pubmed/2425087.

Chen H, Charlat O, Tartaglia LA, Woolf EA, Weng X, Ellis SJ, Lakey ND, Culpepper J, Moore KJ, Breitbart RE, Duyk GM, Tepper RI, Morgenstern JP. Evidence that the diabetes gene encodes the leptin receptor: identification of a mutation in the leptin receptor gene in $\mathrm{db} / \mathrm{db}$ mice [Online]. Cell 84: 491-495, 1996. http://www.ncbi.nlm.nih.gov/pubmed/8608603.

Daneshgari F, Huang X, Liu G, Bena J, Saffore L, Powell CT. Temporal differences in bladder dysfunction caused by diabetes, diuresis, and treated diabetes in mice. Am J Physiol Regul Integr Comp Physiol 290: R1728-35, 2006a.

Daneshgari F, Liu G, Imrey PB. Time Dependent Changes in Diabetic Cystopathy in Rats Include Compensated and Decompensated Bladder Function. J Urol 176: 380-386, 2006b.

Davies M, Brophy S, Williams R, Taylor A. The prevalence, severity, and impact of painful diabetic peripheral neuropathy in type 2 diabetes. Diabetes Care 29: 1518-1522, 2006.

DCCT Research Group the. The absence of a glycemic threshold for the development of long-term complications: the perspective of the Diabetes Control and Complications Trial [Online]. Diabetes 45: 1289-1298, 1996. http://www.ncbi.nlm.nih.gov/pubmed/8826962.

Faerman I, Maler M, Jadzinsky M, Alvarez E, Fox D, Zilbervarg J, Cibeira JB, Colinas R. Asymptomatic neurogenic bladder in juvenile diabetics [Online]. Diabetologia 7: 168-172, 1971. http://www.ncbi.nlm.nih.gov/pubmed/5560918.

Frimodt-Moller C. Diabetic cystopathy: epidemiology and related disorders [Online]. Ann Intern Med 92: 318-321, 1980. http://www.ncbi.nlm.nih.gov/pubmed/7356221.

Garcia VB, Abbinati MD, Harris-Warrick RM, Schulz DJ. Effects of chronic spinal cord injury on relationships among ion channel and receptor mRNAs in mouse lumbar spinal cord. Neuroscience submitted, 2018.

Garcia VB, Garcia ML, Schulz DJ. Quantitative expression profiling in mouse spinal cord reveals changing relationships among channel and receptor mRNA levels across postnatal maturation. Neuroscience 277: 321-333, 2014.

Giachetti A. The functional state of sympathetic nerves in spontaneously diabetic mice [Online]. Diabetes 27: 969-974, 1978. http://www.ncbi.nlm.nih.gov/pubmed/700260.

Golowasch J, Thomas G, Taylor AL, Patel A, Pineda A, Khalil C, Nadim F. Membrane capacitance measurements revisited: dependence of capacitance value on measurement method in nonisopotential neurons. J Neurophysiol 102: 2161-2175, 2009.

Grissmer S, Nguyen AN, Aiyar J, Hanson DC, Mather RJ, Gutman GA, Karmilowicz MJ, Auperin DD, Chandy KG. Pharmacological characterization of five cloned voltage-gated K+ channels, types Kv1.1, 1.2, 1.3, 1.5, and 3.1, stably expressed in mammalian cell lines [Online]. Mol Pharmacol 45: 1227-1234, 1994. http://www.ncbi.nlm.nih.gov/pubmed/7517498.

Gunnarsson R. Function of the pancreatic B-cell during the development of hyperglycaemia in mice 
homozygous for the mutations "diabetes" (db) and "misty" (m) [Online]. Diabetologia 11: 431-438, 1975. http://www.ncbi.nlm.nih.gov/pubmed/1103367.

Hanani M. Satellite glial cells in sympathetic and parasympathetic ganglia: in search of function. Brain Res Rev 64: 304-327, 2010.

Hinder LM, O'Brien PD, Hayes JM, Backus C, Solway AP, Sims-Robinson C, Feldman EL. Dietary reversal of neuropathy in a murine model of prediabetes and metabolic syndrome. Dis Model Mech 10: 717-725, 2017.

Hummel KP, Coleman DL, Lane PW. The influence of genetic background on expression of mutations at the diabetes locus in the mouse. I. C57BL-KsJ and C57BL-6J strains [Online]. Biochem Genet 7: 1-13, 1972. http://www.ncbi.nlm.nih.gov/pubmed/4557514.

Isom LL, Scheuer T, Brownstein AB, Ragsdale DS, Murphy BJ, Catterall WA. Functional coexpression of the beta 1 and type IIA alpha subunits of sodium channels in a mammalian cell line. $J$ Biol Chem 270: 3306-12, 1995.

Kaplan SA, Te AE, Blaivas JG. Urodynamic findings in patients with diabetic cystopathy [Online]. $J$ Urol 153: 342-344, 1995. http://www.ncbi.nlm.nih.gov/pubmed/7815578.

Kebapci N, Yenilmez A, Efe B, Entok E, Demirustu C. Bladder dysfunction in type 2 diabetic patients. Neurourol Urodyn 26: 814-819, 2007.

Lee J-H, Kim E-G, Park B-G, Kim K-H, Cha S-K, Kong ID, Lee J-W, Jeong S-W. Identification of T-Type $\alpha 1 \mathrm{H} \mathrm{Ca}^{2+}$ Channels ( $\mathrm{Ca}_{\mathrm{v}} 3.2$ ) in Major Pelvic Ganglion Neurons. J Neurophysiol 87: 2844-2850, 2002.

Liu PW, Bean BP. Kv2 channel regulation of action potential repolarization and firing patterns in superior cervical ganglion neurons and hippocampal CA1 pyramidal neurons. J Neurosci 34: 4991-5002, 2014.

Liu Y, Sebastian B, Liu B, Zhang Y, Fissel JA, Pan B, Polydefkis M, Farah MH. Sensory and autonomic function and structure in footpads of a diabetic mouse model. Sci Rep 7: 41401, 2017.

Malin SA, Nerbonne JM. Molecular heterogeneity of the voltage-gated fast transient outward K+ current, I(Af), in mammalian neurons [Online]. J Neurosci 21: 8004-8014, 2001. http://www.ncbi.nlm.nih.gov/pubmed/11588173.

Maser RE, Steenkiste AR, Dorman JS, Nielsen VK, Bass EB, Manjoo Q, Drash AL, Becker DJ, Kuller LH, Greene DA, et al. Epidemiological correlates of diabetic neuropathy. Report from Pittsburgh Epidemiology of Diabetes Complications Study [Online]. Diabetes 38: 1456-1461, 1989. http://www.ncbi.nlm.nih.gov/pubmed/2620781.

Mattingly GE, Fischer VW. Peripheral neuropathy following prolonged exposure to streptozotocininduced diabetes in rats: a teased nerve fiber study [Online]. Acta Neuropathol 59: 133-138, 1983. http://www.ncbi.nlm.nih.gov/pubmed/6301203.

Medici F, Hawa M, Ianari A, Pyke DA, Leslie RD. Concordance rate for type II diabetes mellitus in monozygotic twins: actuarial analysis. Diabetologia 42: 146-150, 1999.

Metz AE, Jarsky T, Martina M, Spruston N. R-Type Calcium Channels Contribute to Afterdepolarization and Bursting in Hippocampal CA1 Pyramidal Neurons [Online]. J Neurosci 25, 2005. http://www.jneurosci.org/content/25/24/5763/tab-figures-data [25 Jun. 2018].

Nadelhaft I, Vera PL. Reduced urinary bladder afferent conduction velocities in streptozocin diabetic 
rats [Online]. Neurosci Lett 135: 276-278, 1992. http://www.ncbi.nlm.nih.gov/pubmed/1625809.

Naundorf B, Wolf F, Volgushev M. Unique features of action potential initiation in cortical neurons. Nature 440: 1060-1063, 2006.

Perez-Reyes E. Molecular Physiology of Low-Voltage-Activated T-type Calcium Channels. Physiol Rev 83: 117-161, 2003.

Platkiewicz J, Brette R. A threshold equation for action potential initiation. PLoS Comput Biol 6: e1000850, 2010.

Platkiewicz J, Brette R. Impact of fast sodium channel inactivation on spike threshold dynamics and synaptic integration. PLoS Comput Biol 7: e1001129, 2011.

Rudy B, McBain CJ. Kv3 channels: voltage-gated K+ channels designed for high-frequency repetitive firing [Online]. Trends Neurosci 24: 517-526, 2001. http://www.ncbi.nlm.nih.gov/pubmed/11506885.

Sasaki K, Chancellor MB, Goins WF, Phelan MW, Glorioso JC, de Groat WC, Yoshimura N. Gene therapy using replication-defective herpes simplex virus vectors expressing nerve growth factor in a rat model of diabetic cystopathy [Online]. Diabetes 53: 2723-2730, 2004. http://www.ncbi.nlm.nih.gov/pubmed/15448108.

Sasaki K, Chancellor MB, Phelan MW, Yokoyama T, Fraser MO, Seki S, Kubo K, Kumon H, Groat WC, Yoshimura N. Diabetic cystopathy correlates with a long-term decrease in nerve growth factor levels in the bladder and lumbosacral dorsal root Ganglia. J Urol 168: 1259-1264, 2002.

Springer MG, Kullmann PH, Horn JP. Virtual leak channels modulate firing dynamics and synaptic integration in rat sympathetic neurons: implications for ganglionic transmission in vivo. J Physiol 593: 803-823, 2015.

Sullivan KA, Hayes JM, Wiggin TD, Backus C, Su Oh S, Lentz SI, Brosius 3rd F, Feldman EL. Mouse models of diabetic neuropathy. Neurobiol Dis 28: 276-285, 2007.

Suzuki S, Rogawski MA. T-type calcium channels mediate the transition between tonic and phasic firing in thalamic neurons [Online]. Proc Natl Acad Sci U S A 86: 7228-7232, 1989.

http://www.ncbi.nlm.nih.gov/pubmed/2550936.

Tompkins JD, Vizzard MA, Parsons RL. Synaptic transmission at parasympathetic neurons of the major pelvic ganglion from normal and diabetic male mice. J Neurophysiol 109: 988-995, 2013.

UKPDS. Intensive blood-glucose control with sulphonylureas or insulin compared with conventional treatment and risk of complications in patients with type 2 diabetes (UKPDS 33). UK Prospective Diabetes Study (UKPDS) Group [Online]. Lancet 352: 837-853, 1998. http://www.ncbi.nlm.nih.gov/pubmed/9742976.

\section{United States. Department of Health and Human Services., Center for Disease Control., National} Center for Health Statistics (U.S.). Health, United States, 2016 $\square$ : with chartbook on Long-term Trends in Health [Online]. Hyattsville, MD: National Center for Health Statistics. https://www.cdc.gov/nchs/data/hus/hus16.pdf.

Vacher H, Mohapatra DP, Trimmer JS. Localization and Targeting of Voltage-Dependent Ion Channels in Mammalian Central Neurons. Physiol Rev 88: 1407-1447, 2008.

Vandesompele J, De Preter K, Pattyn I, Poppe B, Van Roy N, De Paepe A, Speleman R. Accurate normalization of real-time quantitative RT-PCR data by geometric averaging of multiple internal control genes. Genome Biol 3: research0034.1-0034.11, 2002. 
824 Vinik AI, Maser RE, Mitchell BD, Freeman R. Diabetic autonomic neuropathy [Online]. Diabetes

825 Care 26: 1553-1579, 2003. http://www.ncbi.nlm.nih.gov/pubmed/12716821.

826 Vinik AI, Maser RE, Ziegler D. Autonomic imbalance: prophet of doom or scope for hope? Diabet Med 827 28: 643-651, 2011.

828 Wang B, Chandrasekera PC, Pippin JJ. Leptin- and leptin receptor-deficient rodent models: relevance 829 for human type 2 diabetes [Online]. Curr Diabetes Rev 10: 131-145, 2014.

830 http://www.ncbi.nlm.nih.gov/pubmed/24809394.

831 Weiser M, Vega-Saenz de Miera E, Kentros C, Moreno H, Franzen L, Hillman D, Baker H, Rudy

832 B. Differential expression of Shaw-related $\mathrm{K}+$ channels in the rat central nervous system [Online]. $J$

833 Neurosci 14: 949-972, 1994. http://www.ncbi.nlm.nih.gov/pubmed/8120636.

834 White WE, Hooper SL. Contamination of current-clamp measurement of neuron capacitance by voltage835 dependent phenomena. J Neurophysiol 110: 257-268, 2013.

836 Won YJ, Whang K, Kong ID, Park KS, Lee JW, Jeong SW. Expression profiles of high voltage837 activated calcium channels in sympathetic and parasympathetic pelvic ganglion neurons innervating the 838 urogenital system. J Pharmacol Exp Ther 317: 1064-1071, 2006.

839 Yuan Z, Tang Z, He C, Tang W. Diabetic cystopathy: A review. J Diabetes 7: 442-447, 2015. 


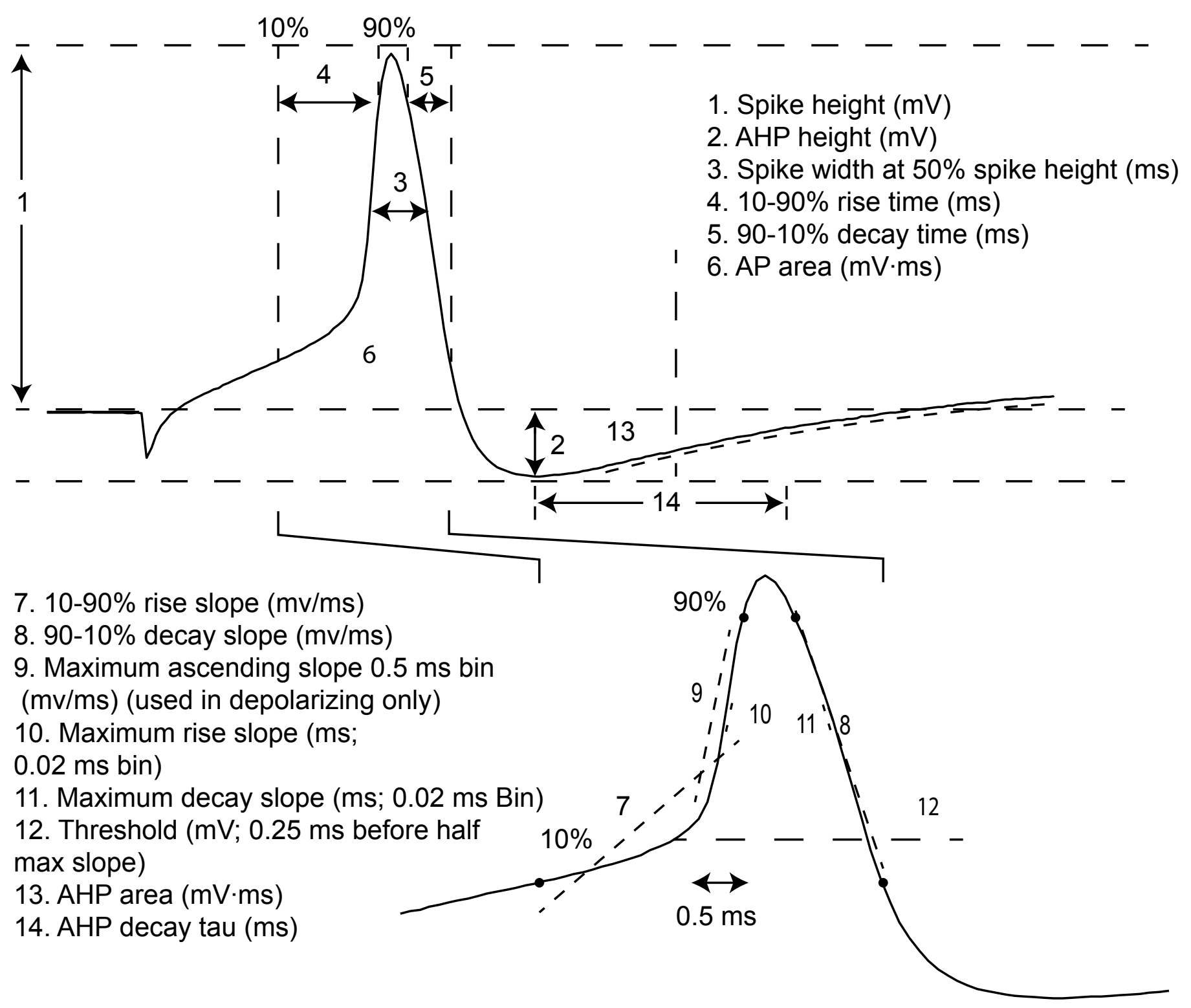


A

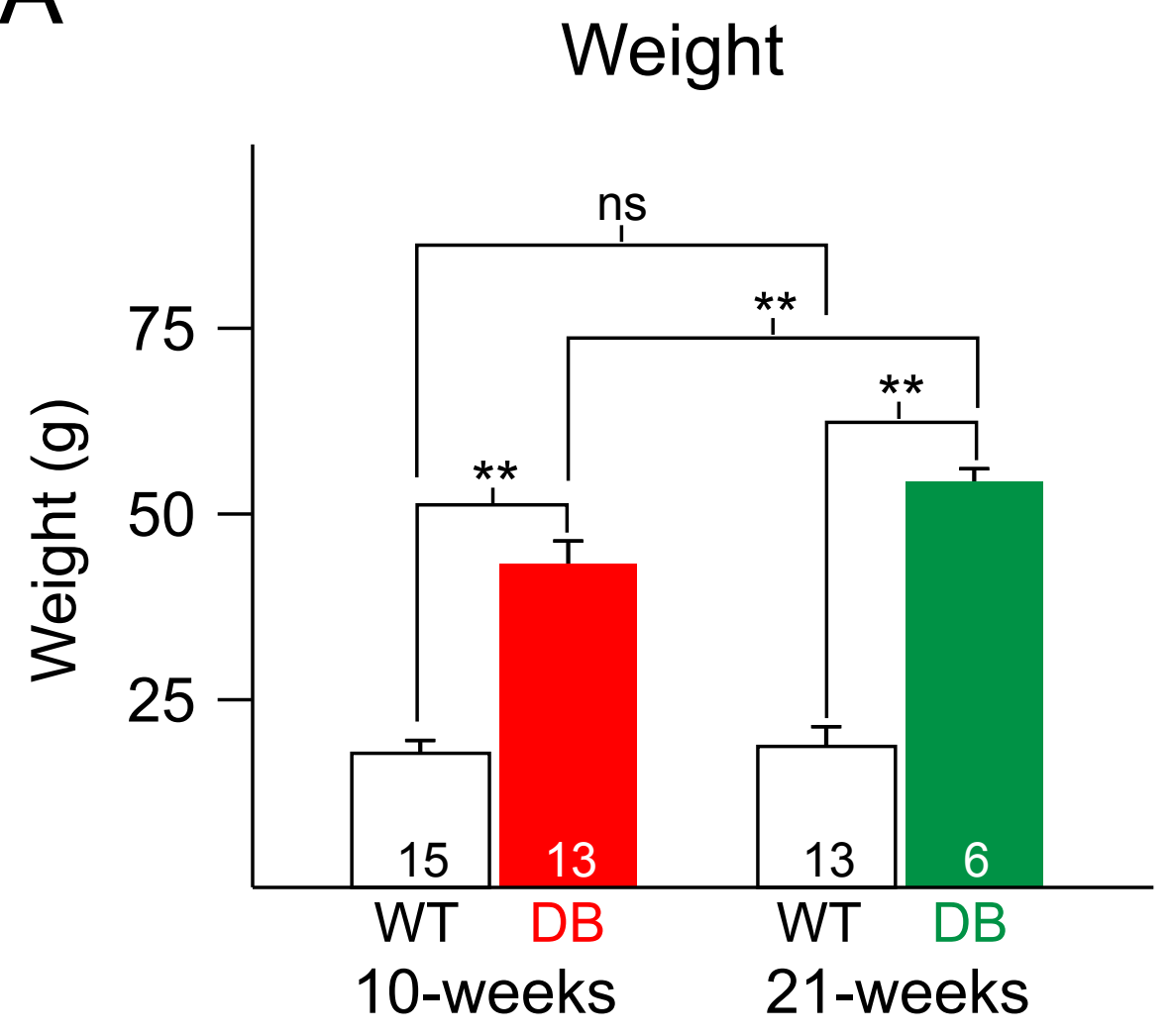

B

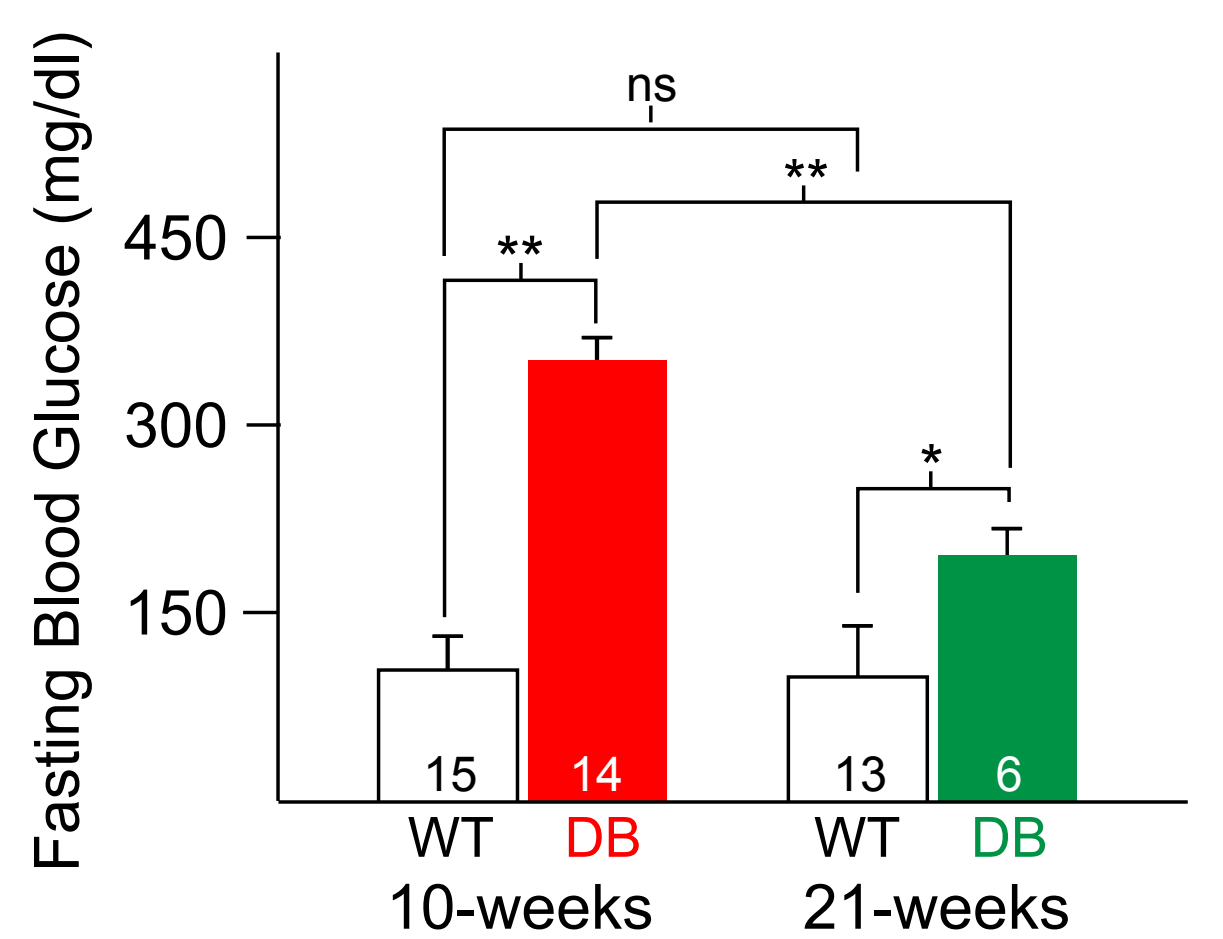

C

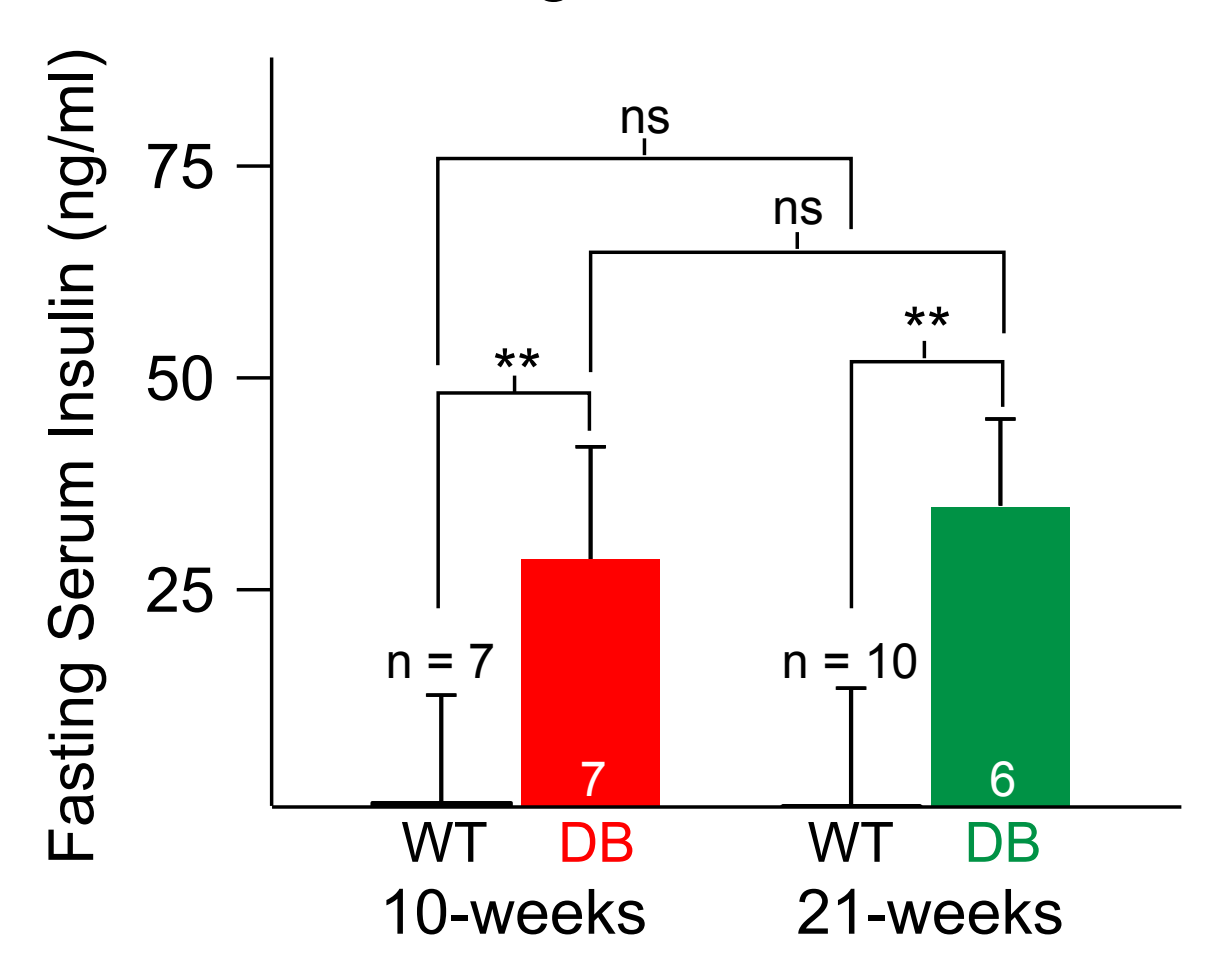




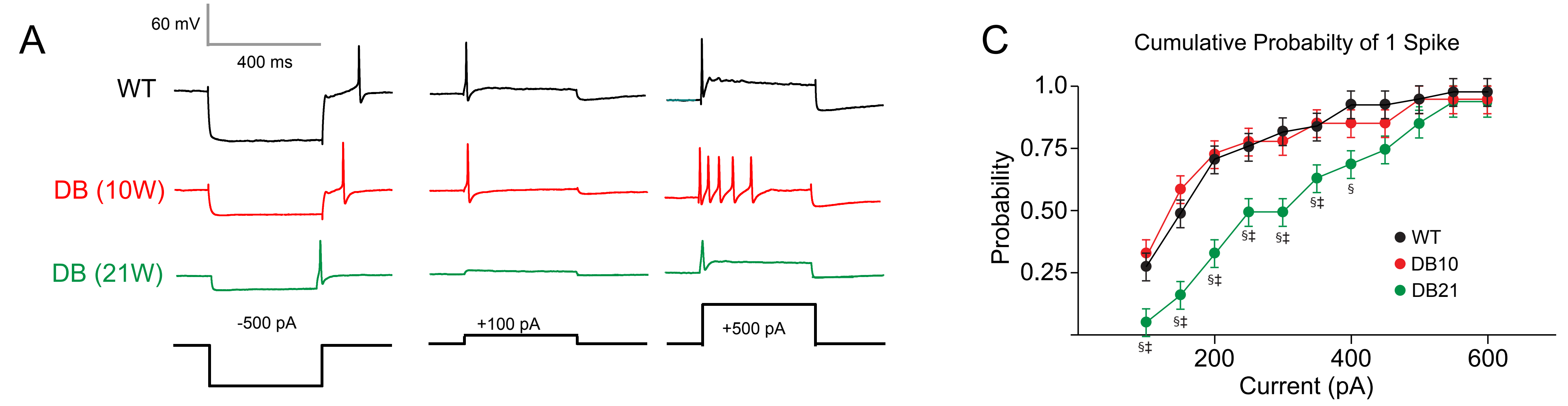

B

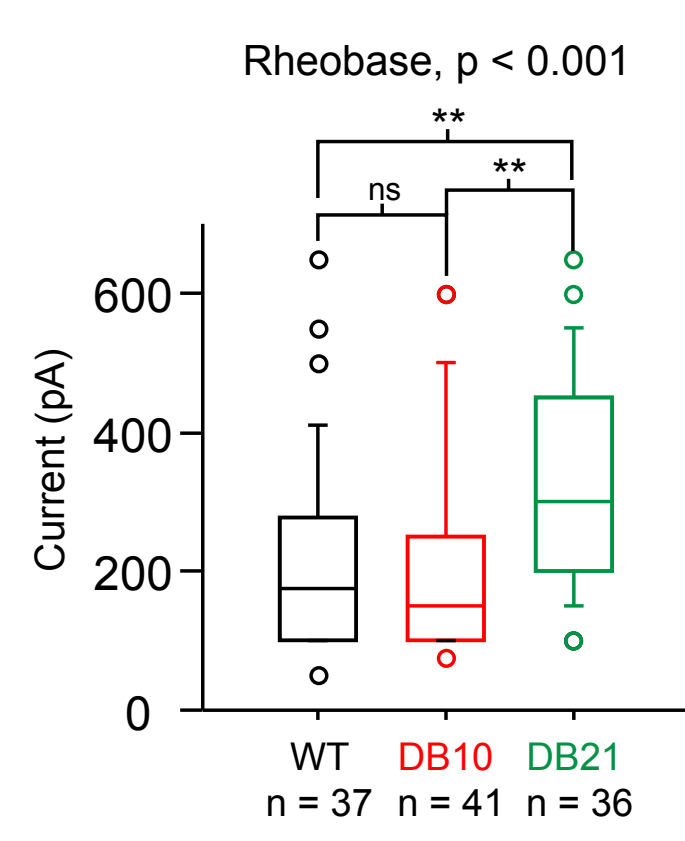

Threshold, $p=0.009$

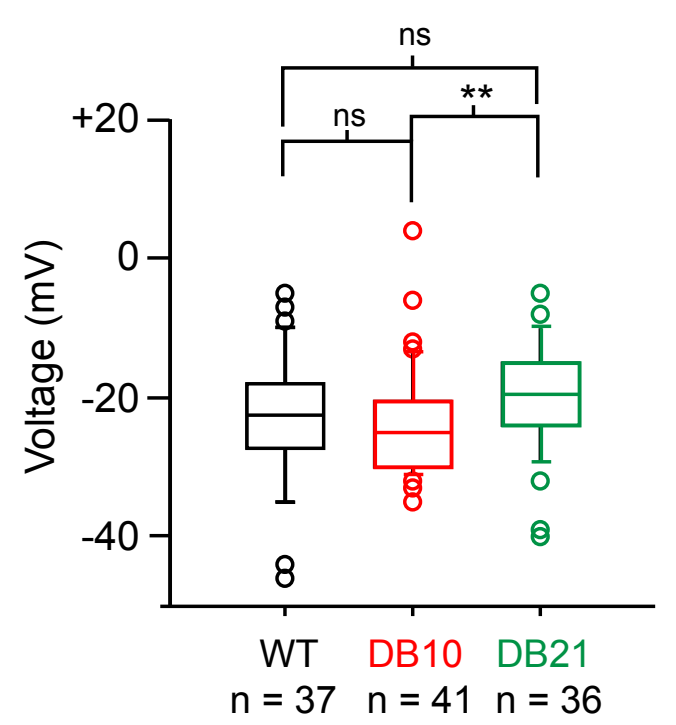

Rebound Spike Latency, $\mathrm{p}<0.001$

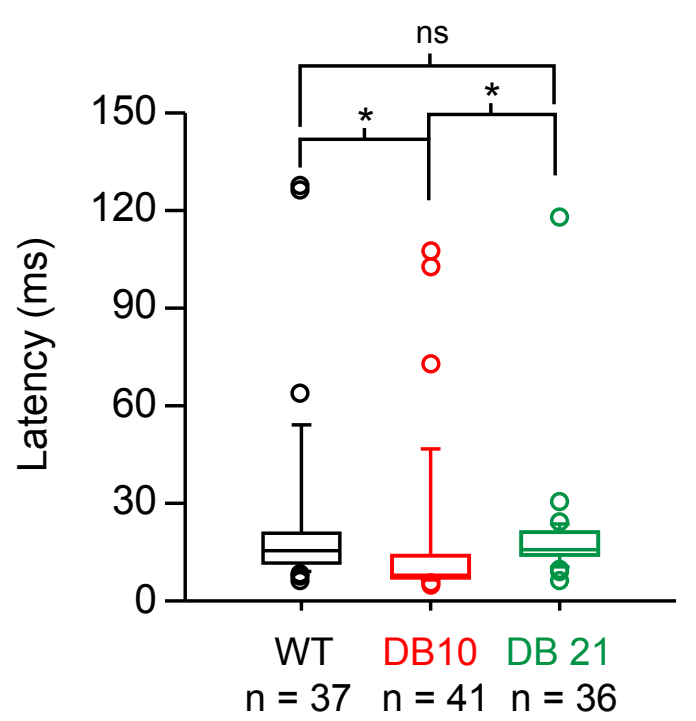

Cumulative Probabilty of 2 Spikes

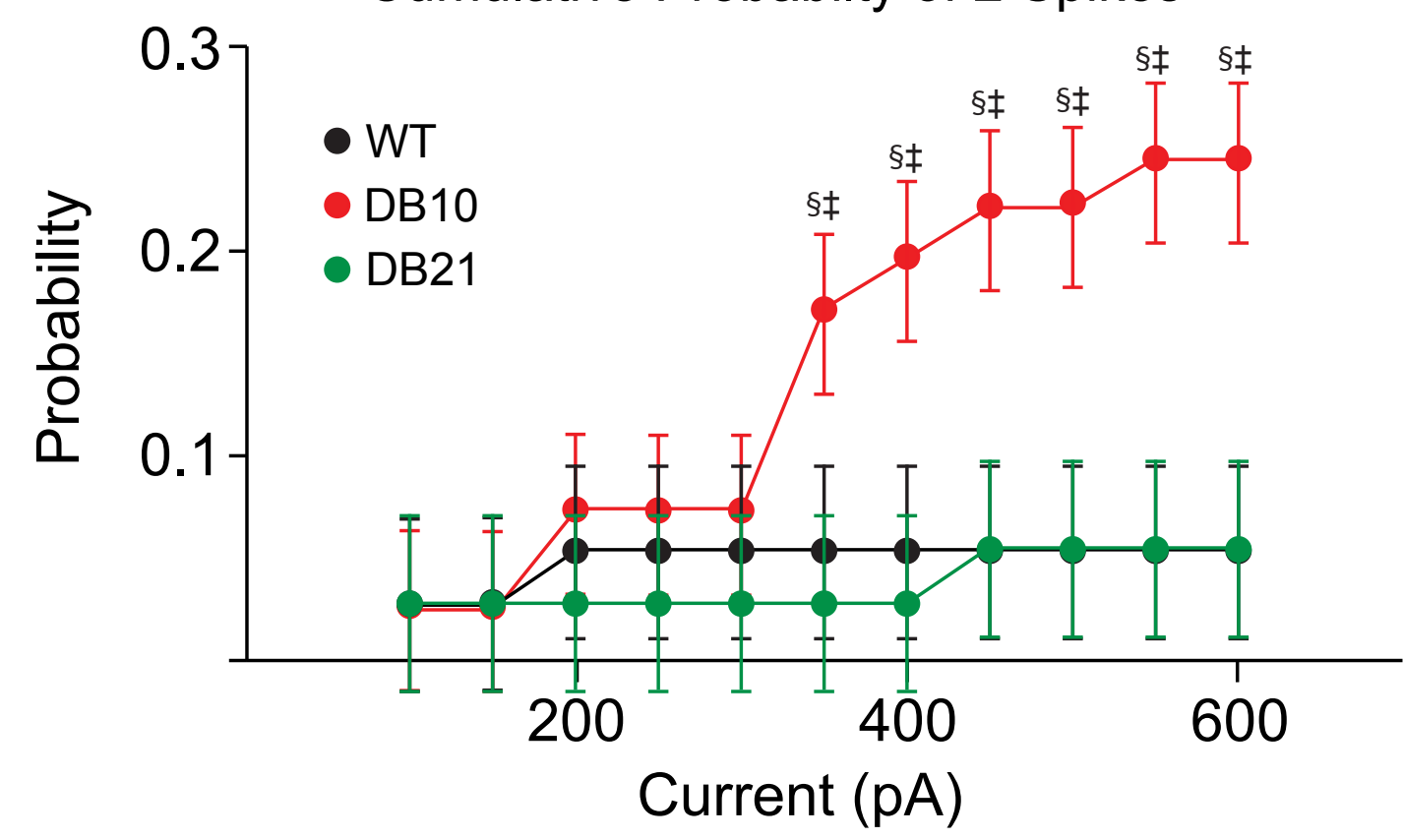


A Resting Membrane

Potential, $p=0.365$

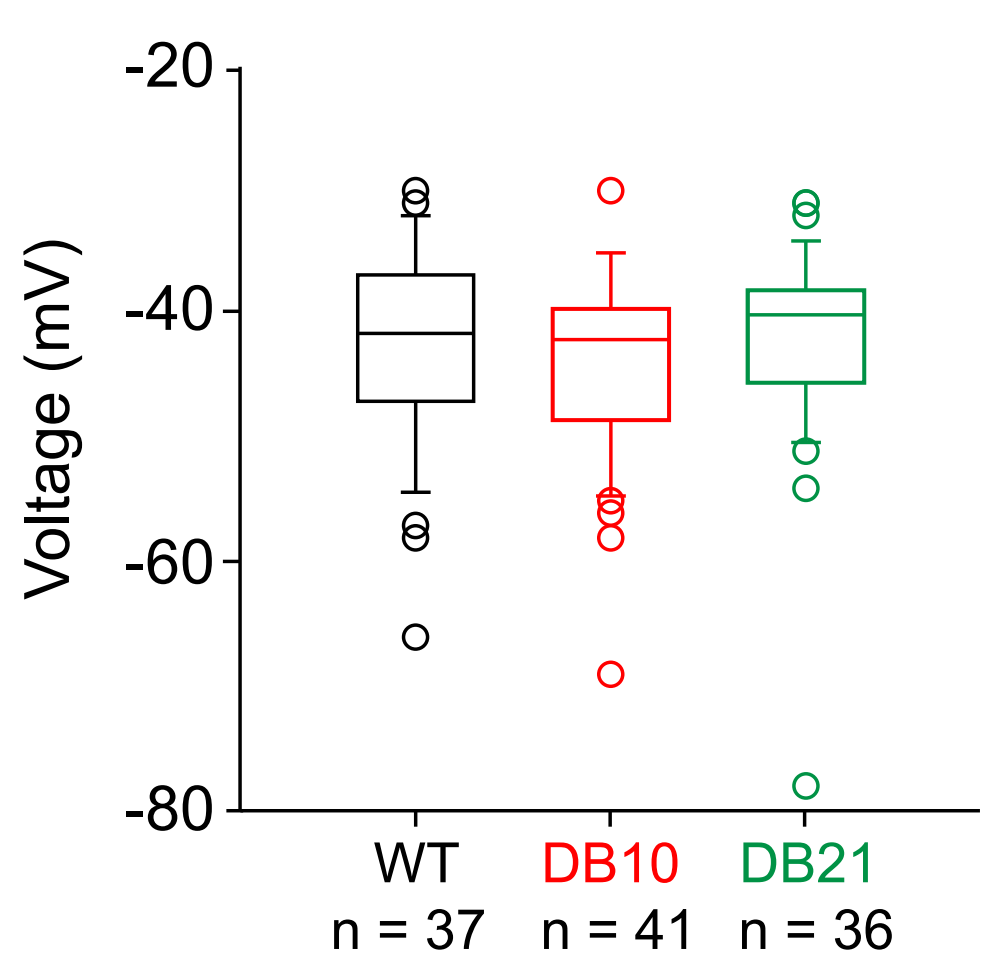

B

$R_{\text {in }}, p=0.005$

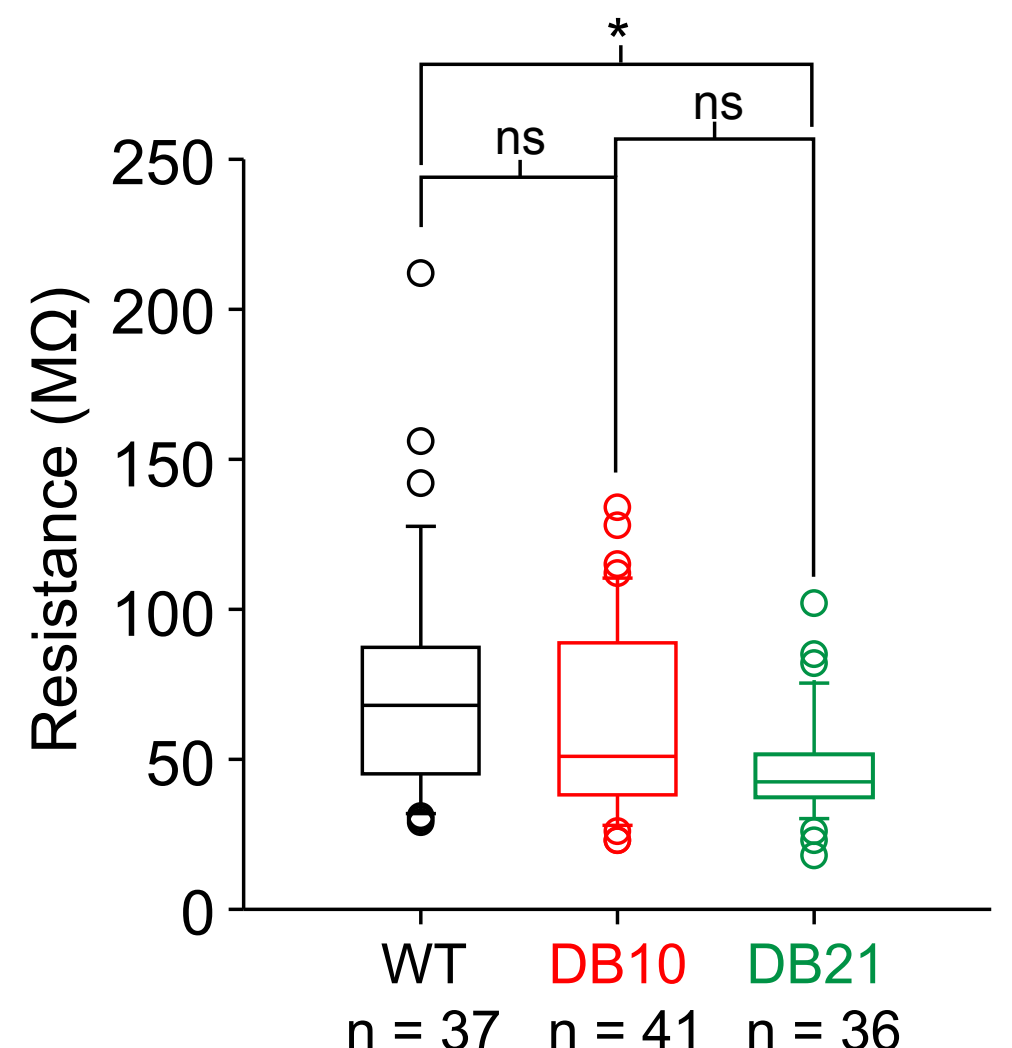

Tau, $p=0.033$

C

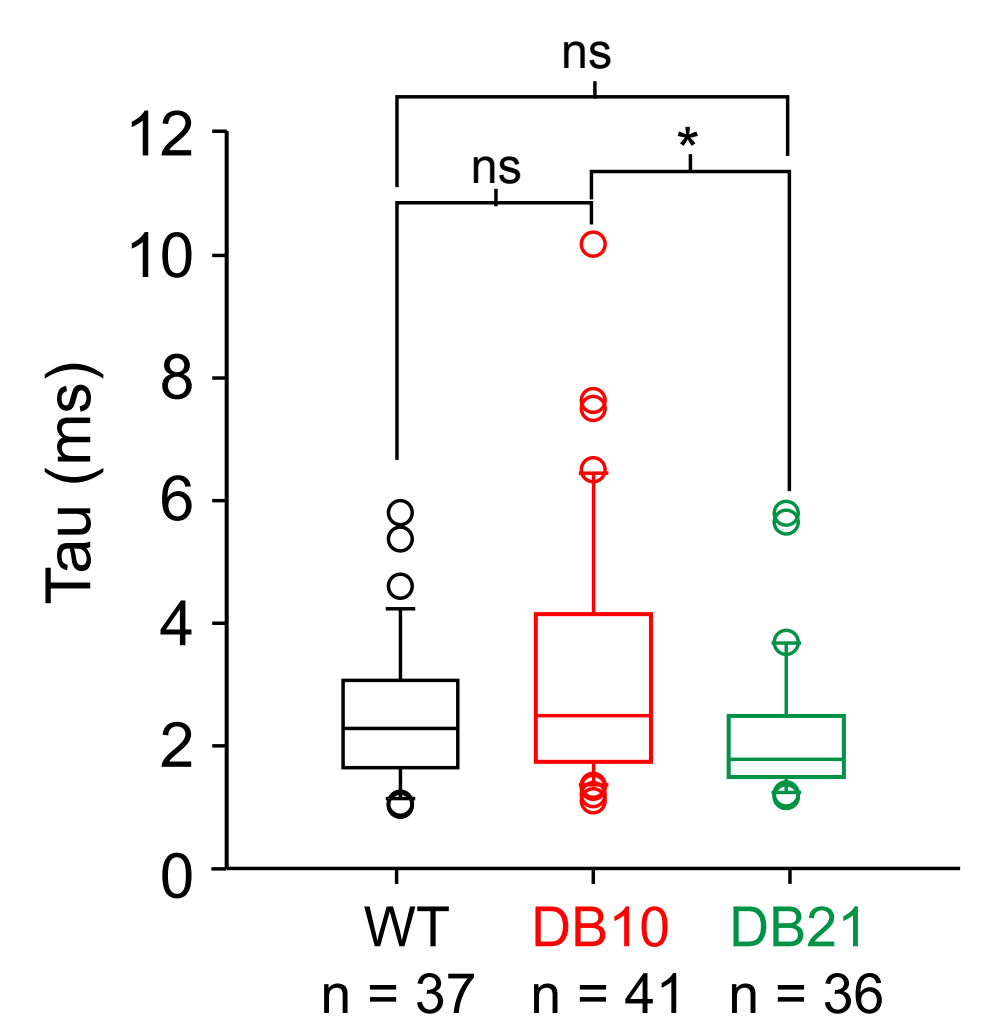

Capacitance, $p<0.001$

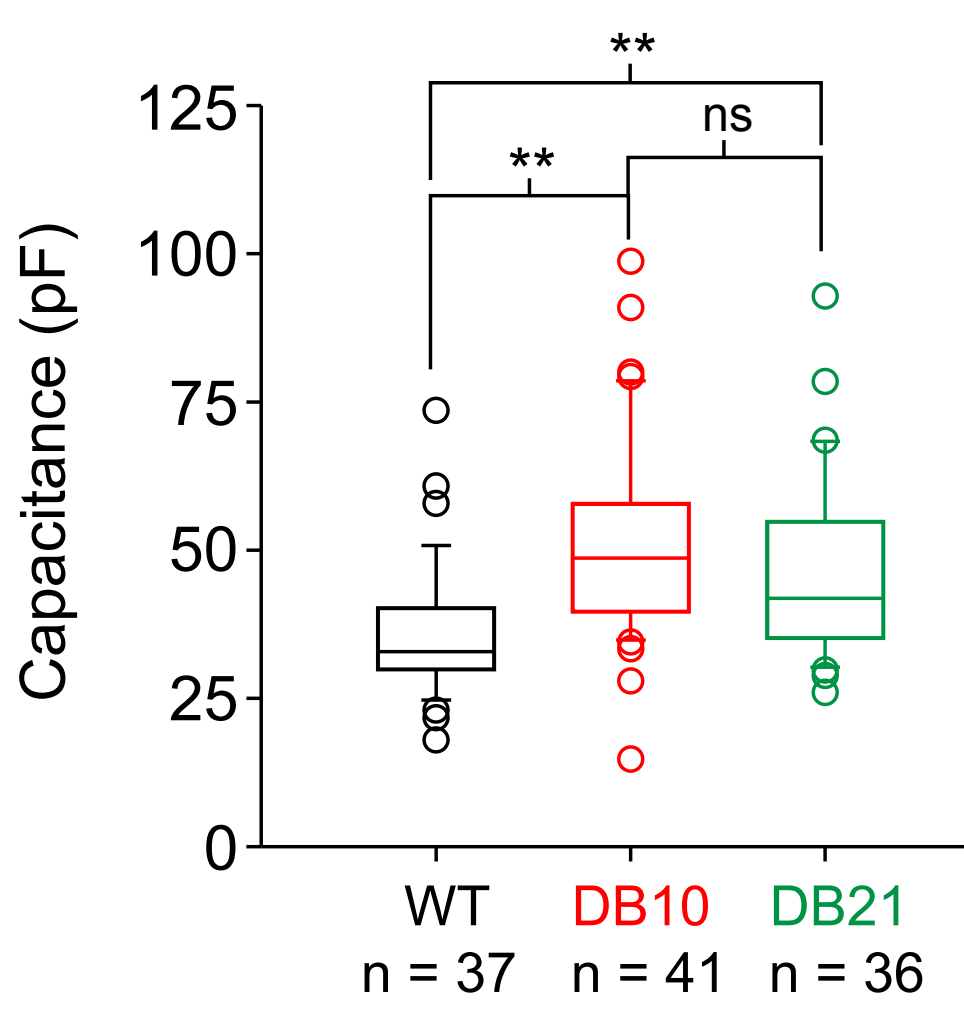


A Spike Slope Ascending (depolarizing), $p<0.001$

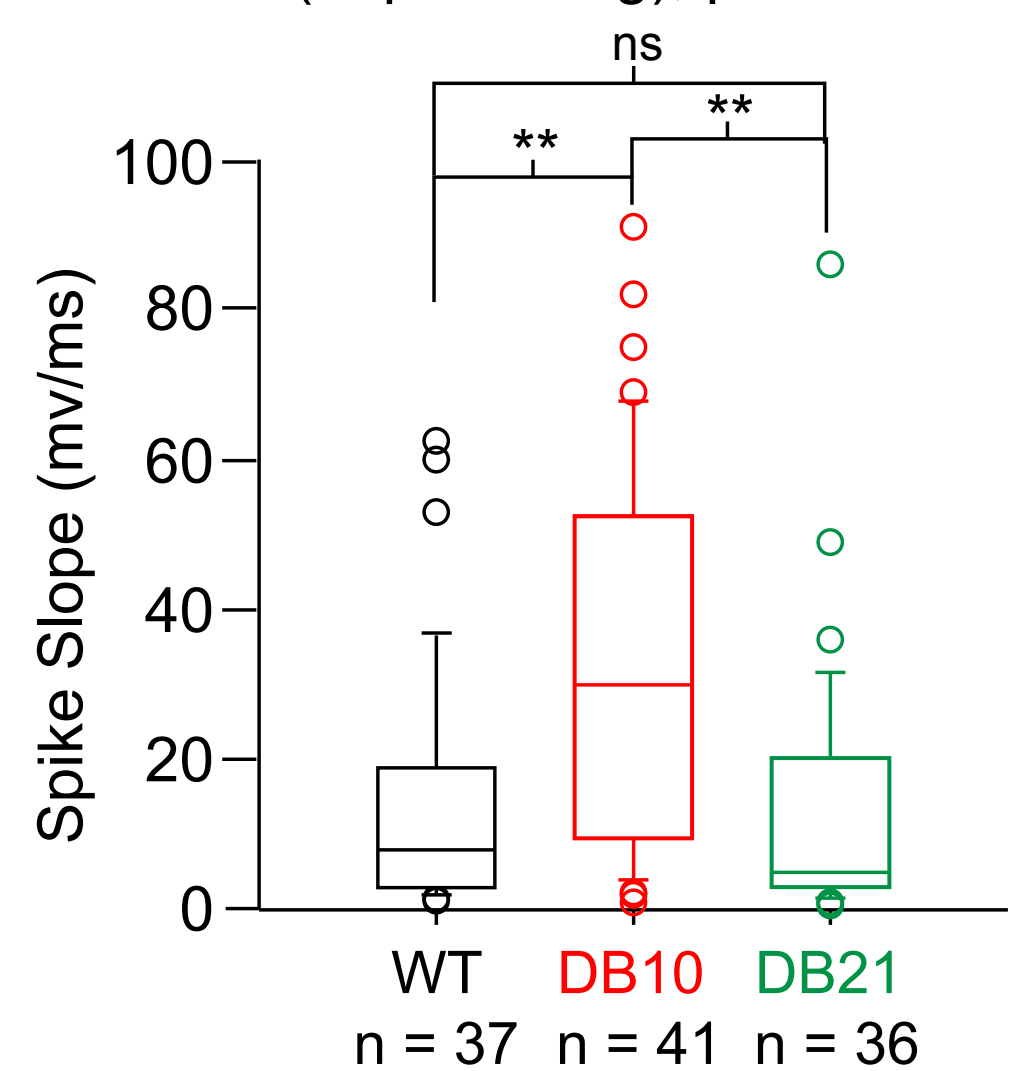

B

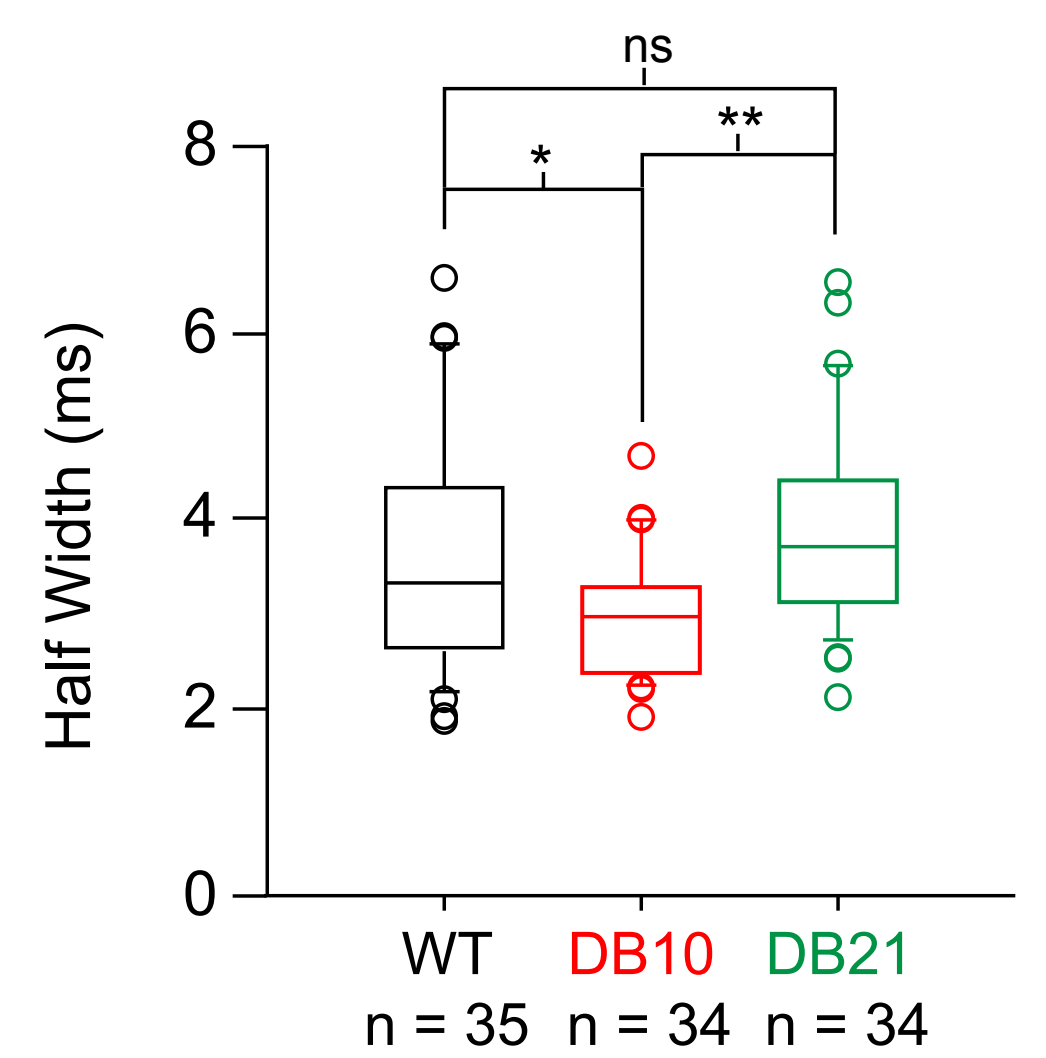

C Max Rise Slope (rebound), $p=0.059$

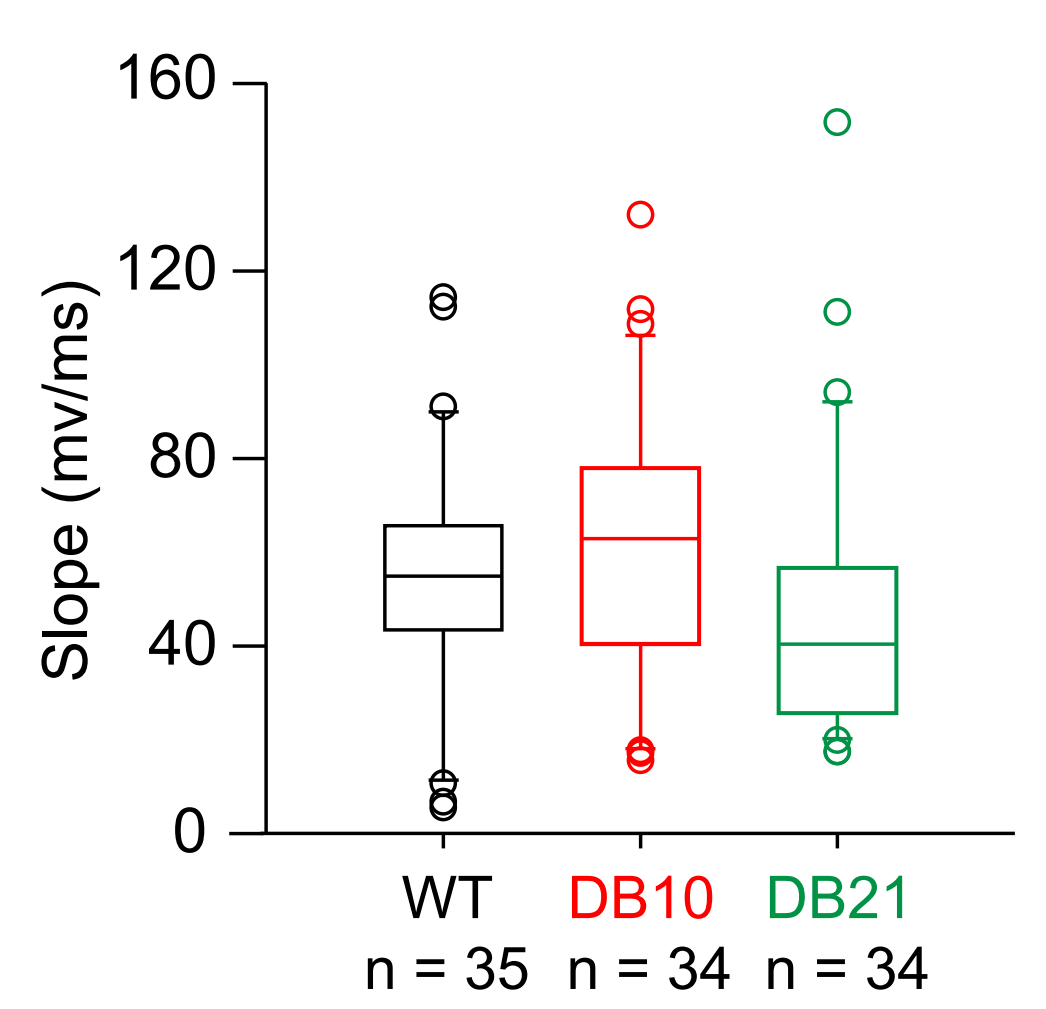

G 10-90\% Rise Slope,

$$
\mathrm{p}=0.360
$$

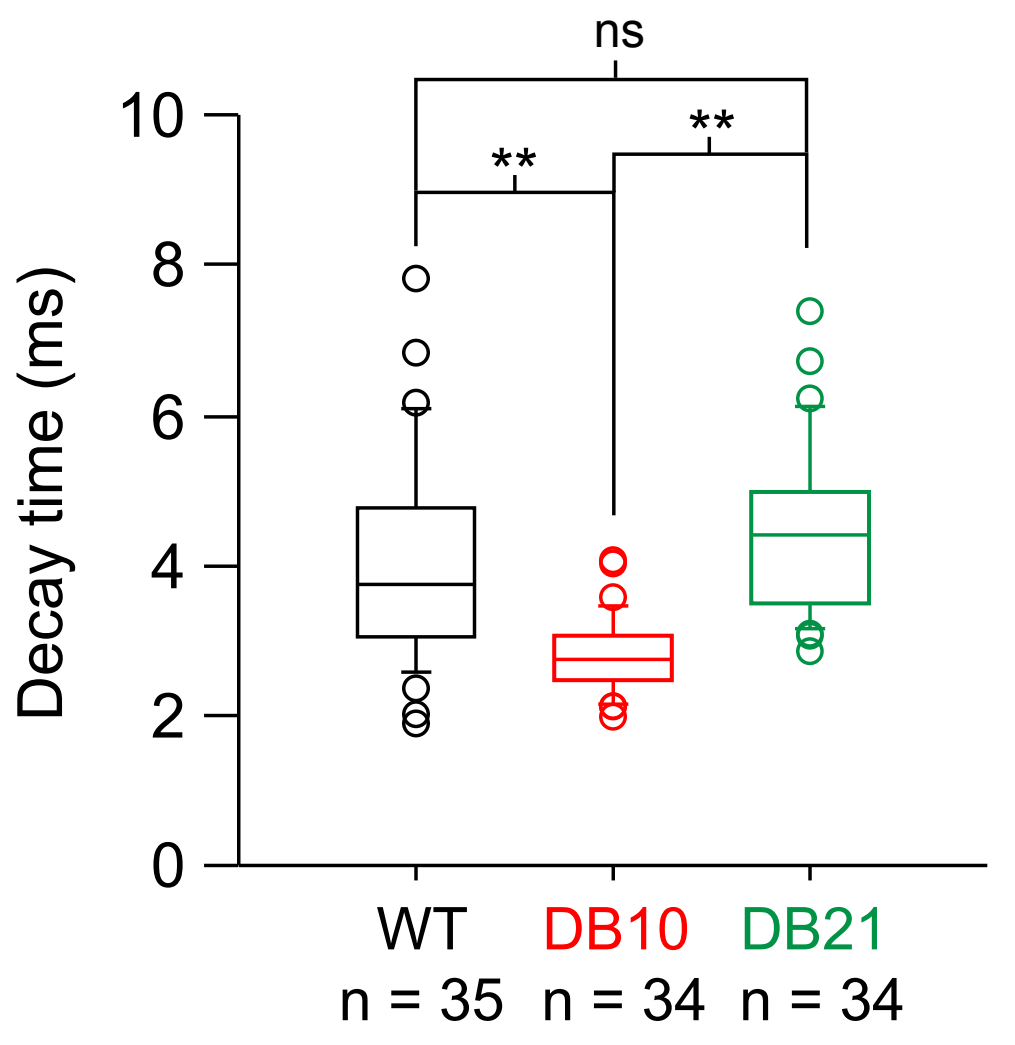

$J$

AHP Area, $p=0.767$

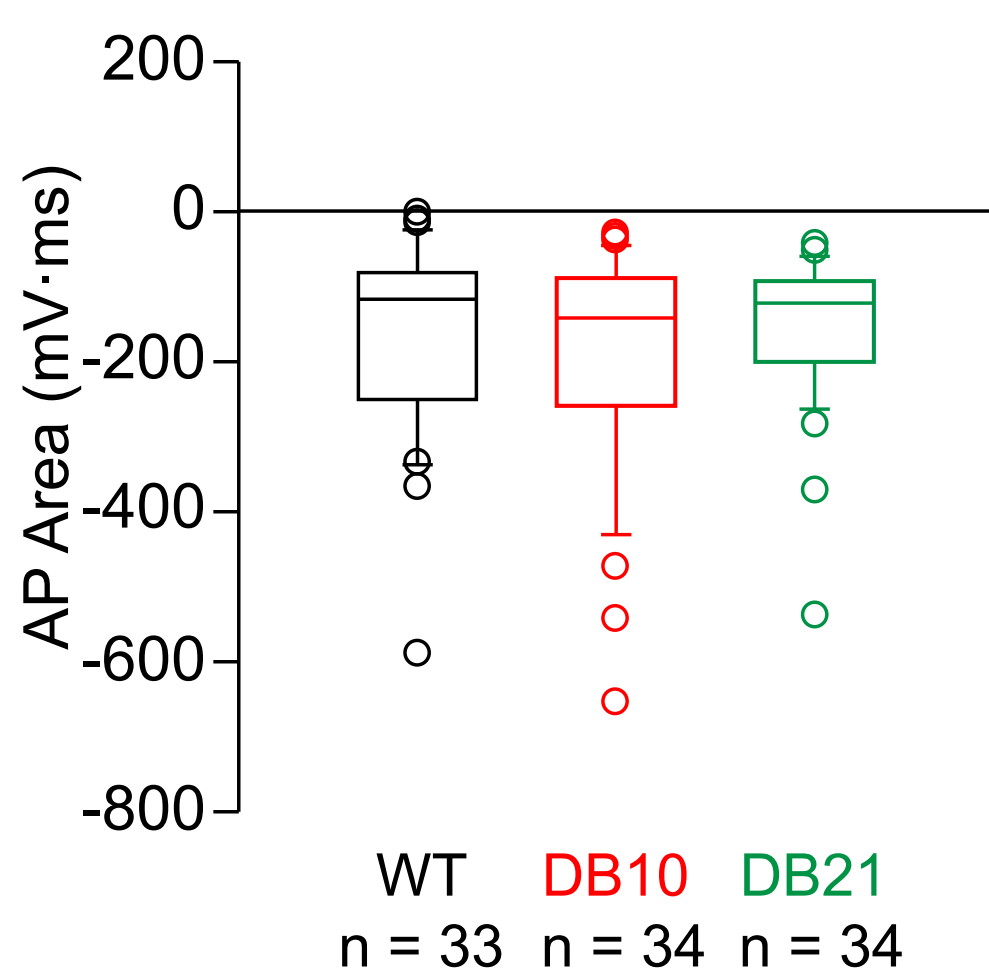

K

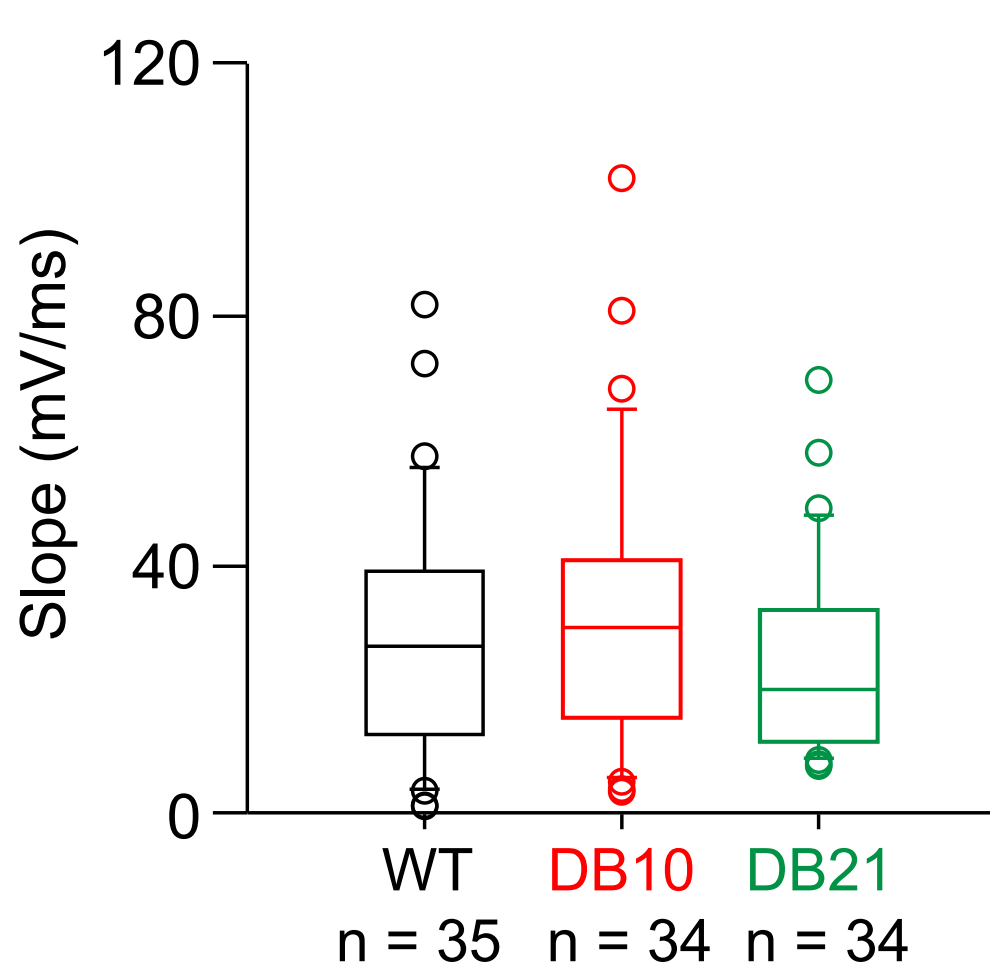

AHP Amplitude, $p=0.235$

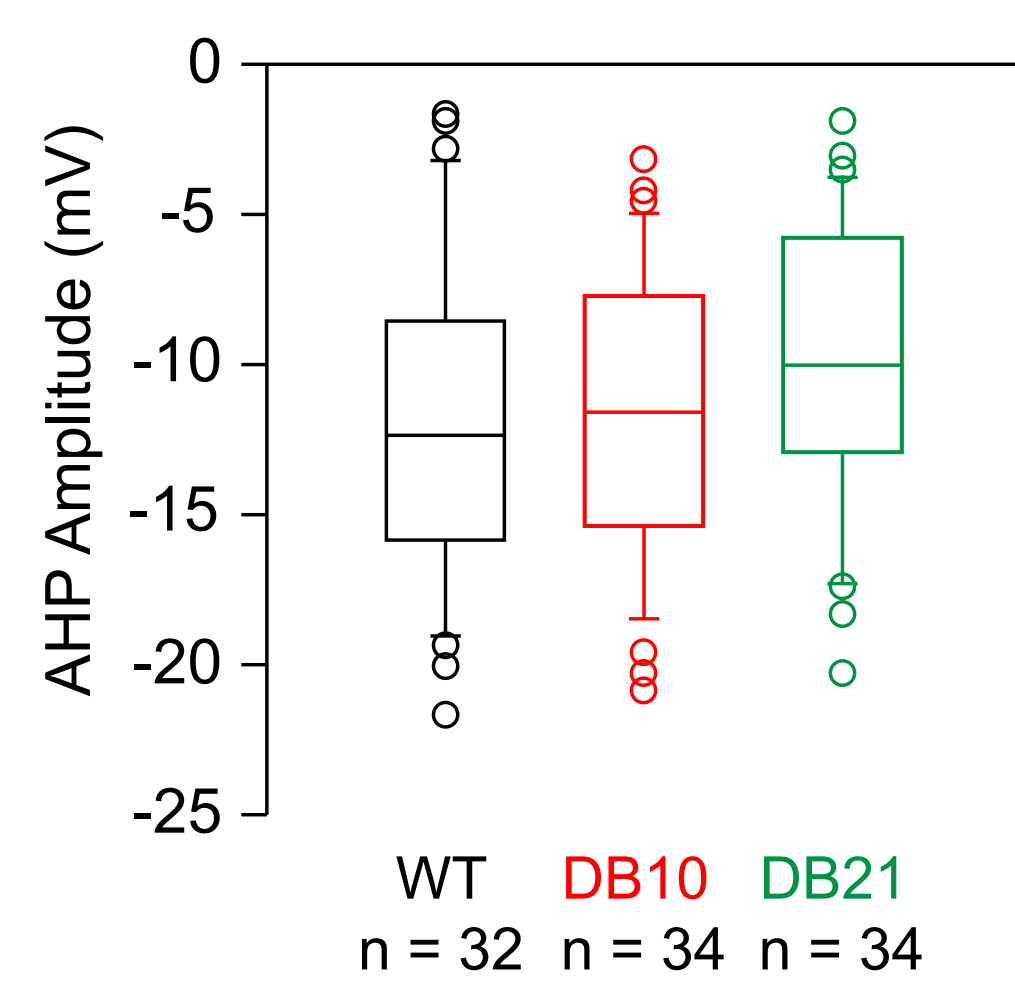

D Max Decay Slope (Rebound) $p=0.016$

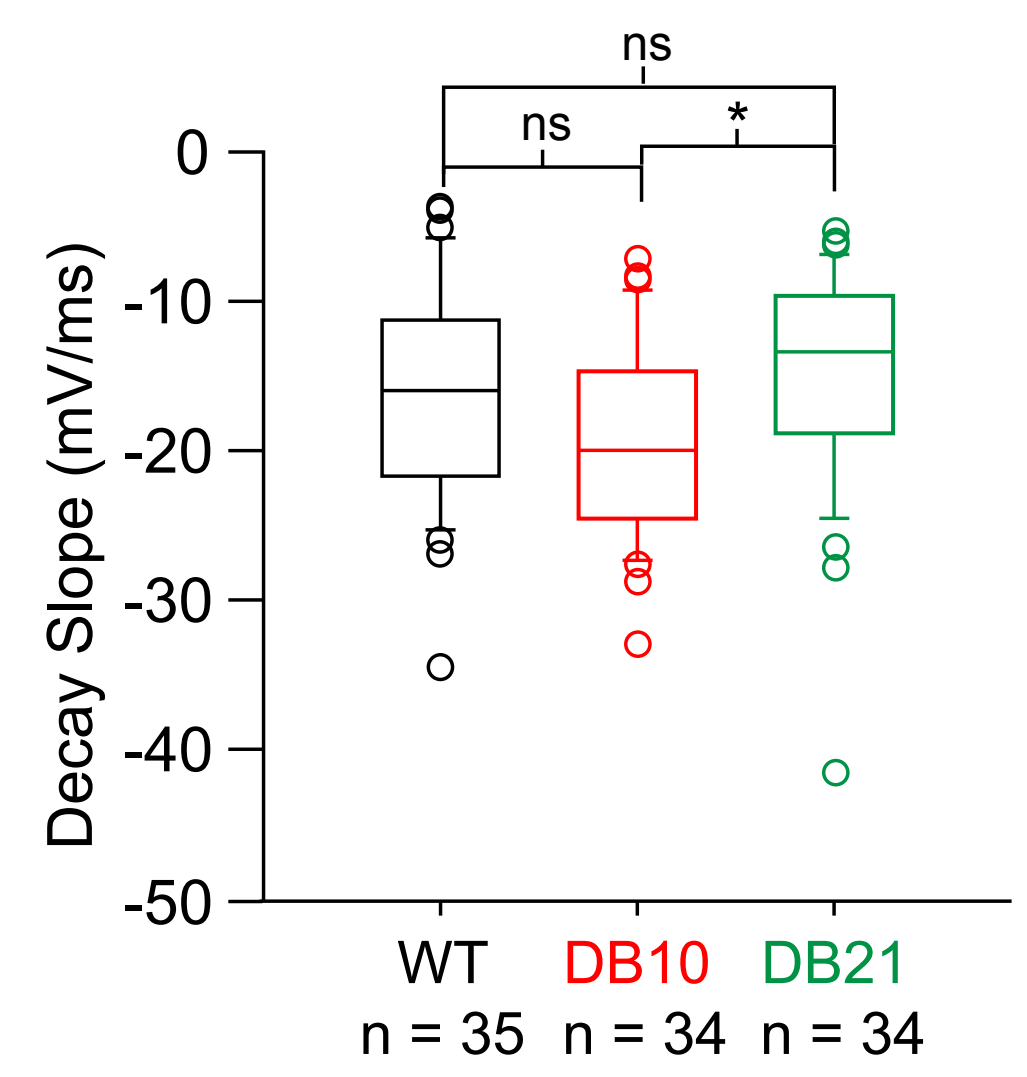

H 90-10\% Decay slope,

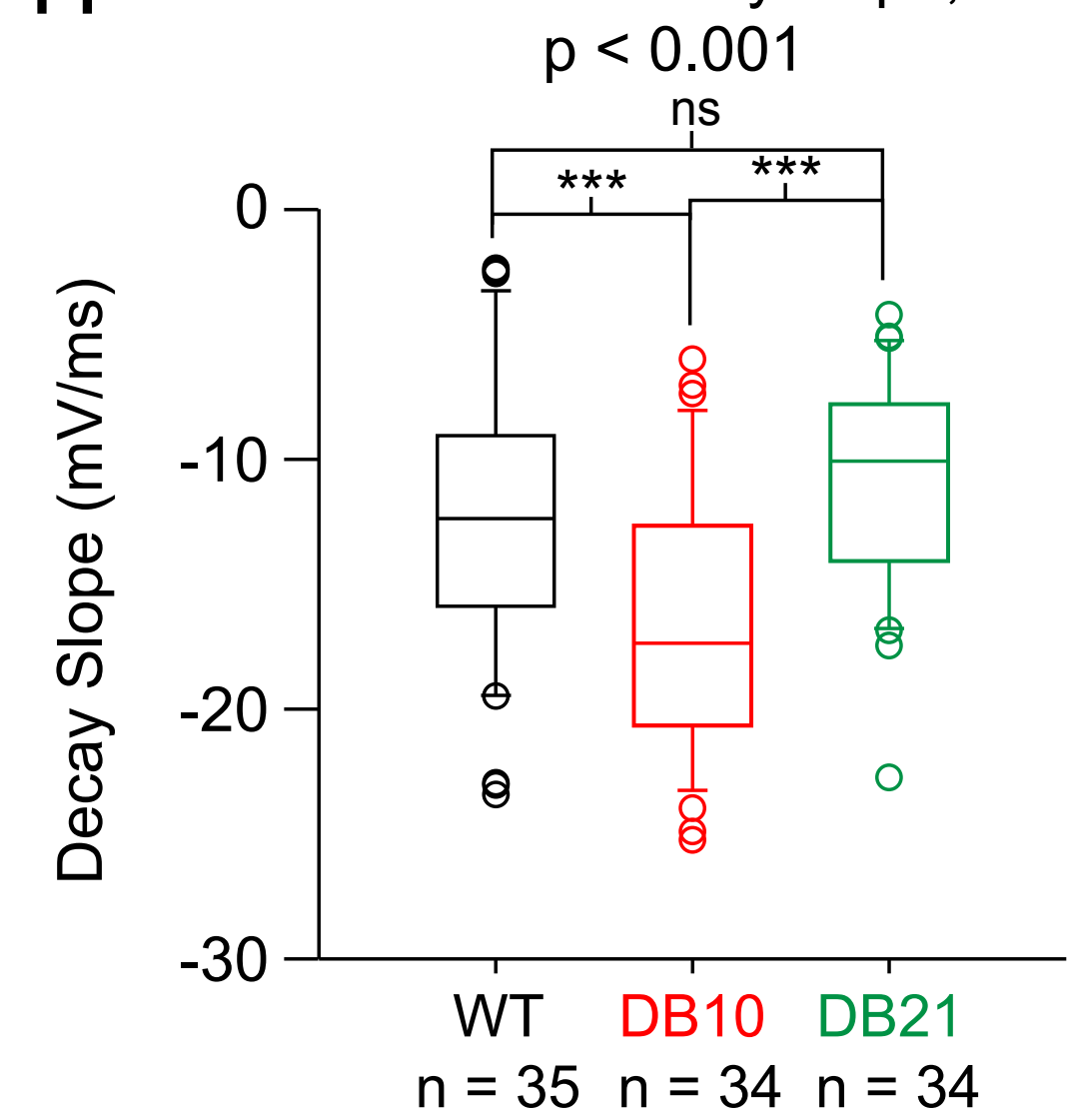

L

AHP Tau,
$p=0.003$

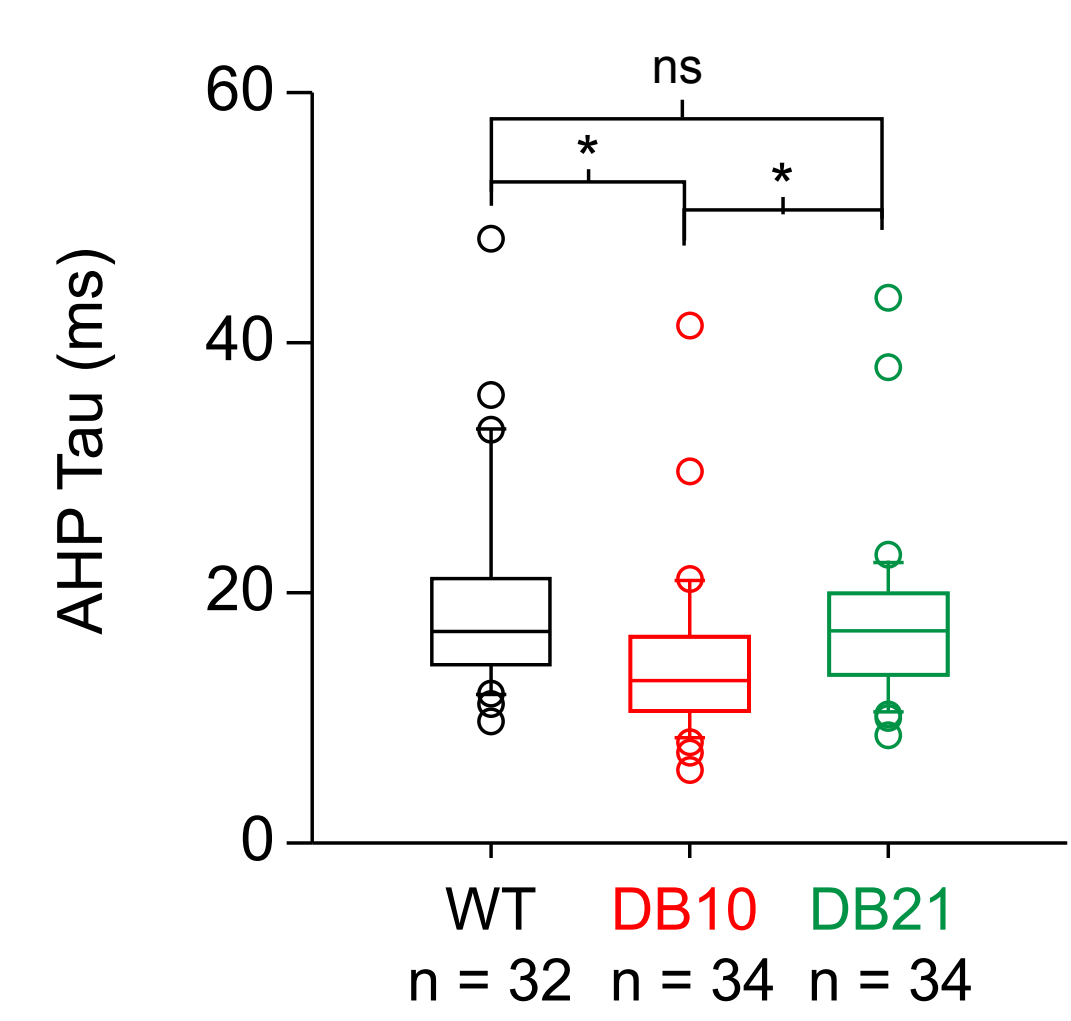

AP Area, $p=0.002$

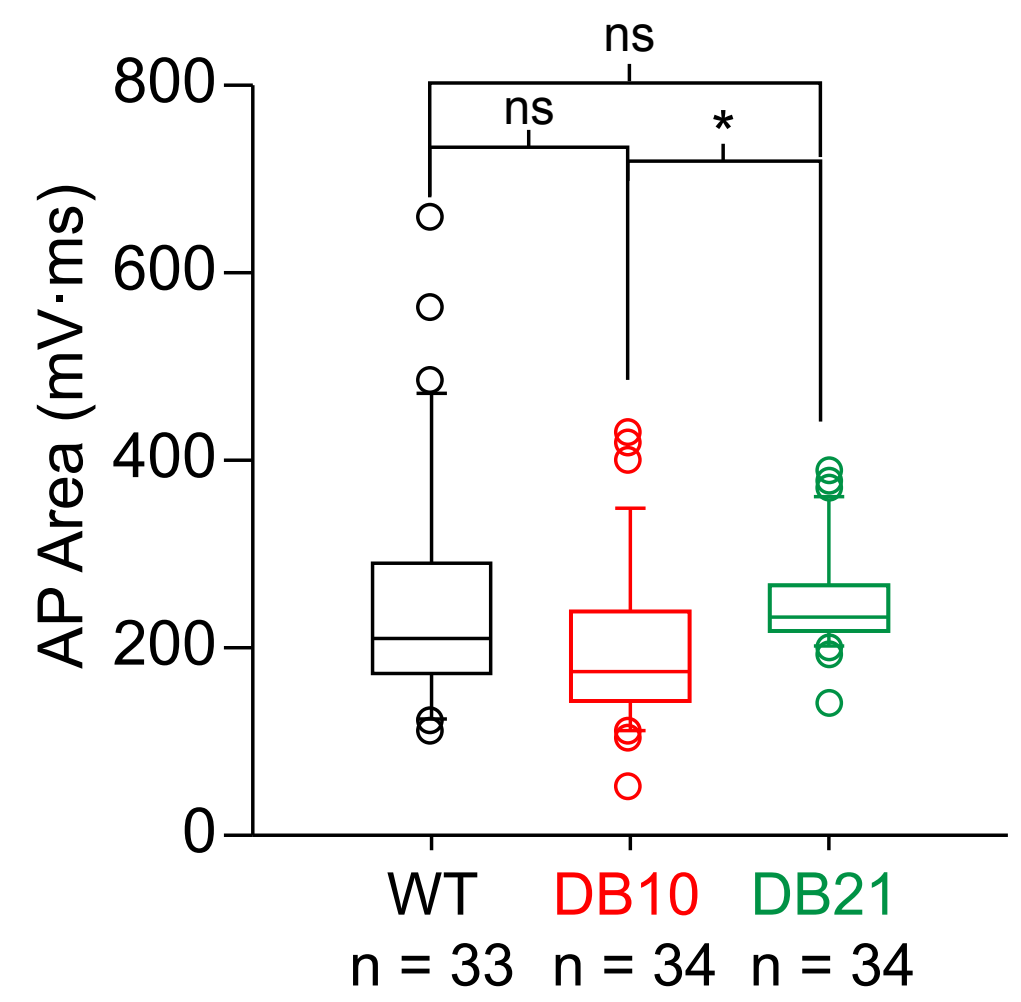


Calcium
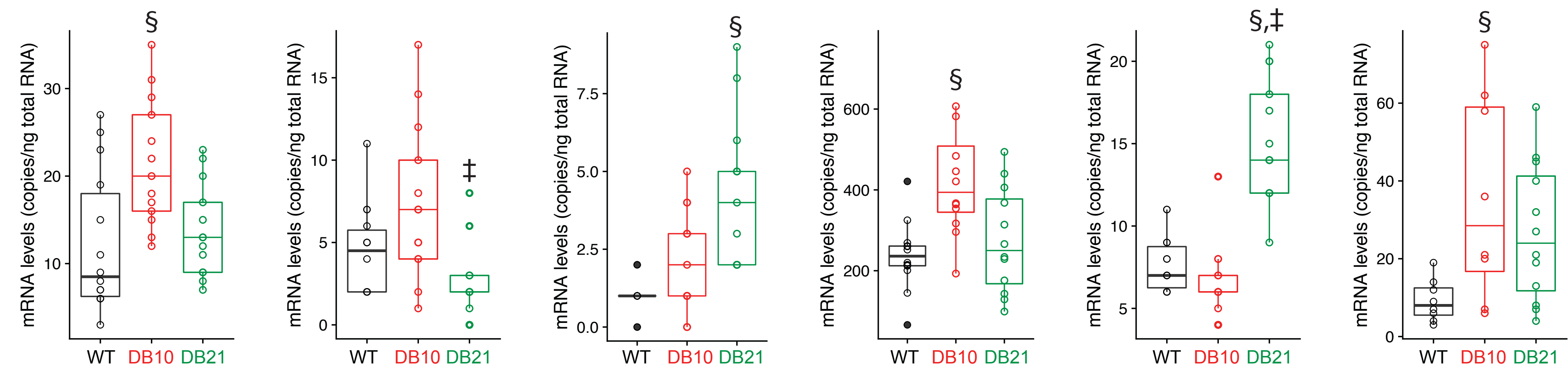

$\operatorname{SCN} 3 A$

SCN7A

SCN9A

SCNM1

SCN1B
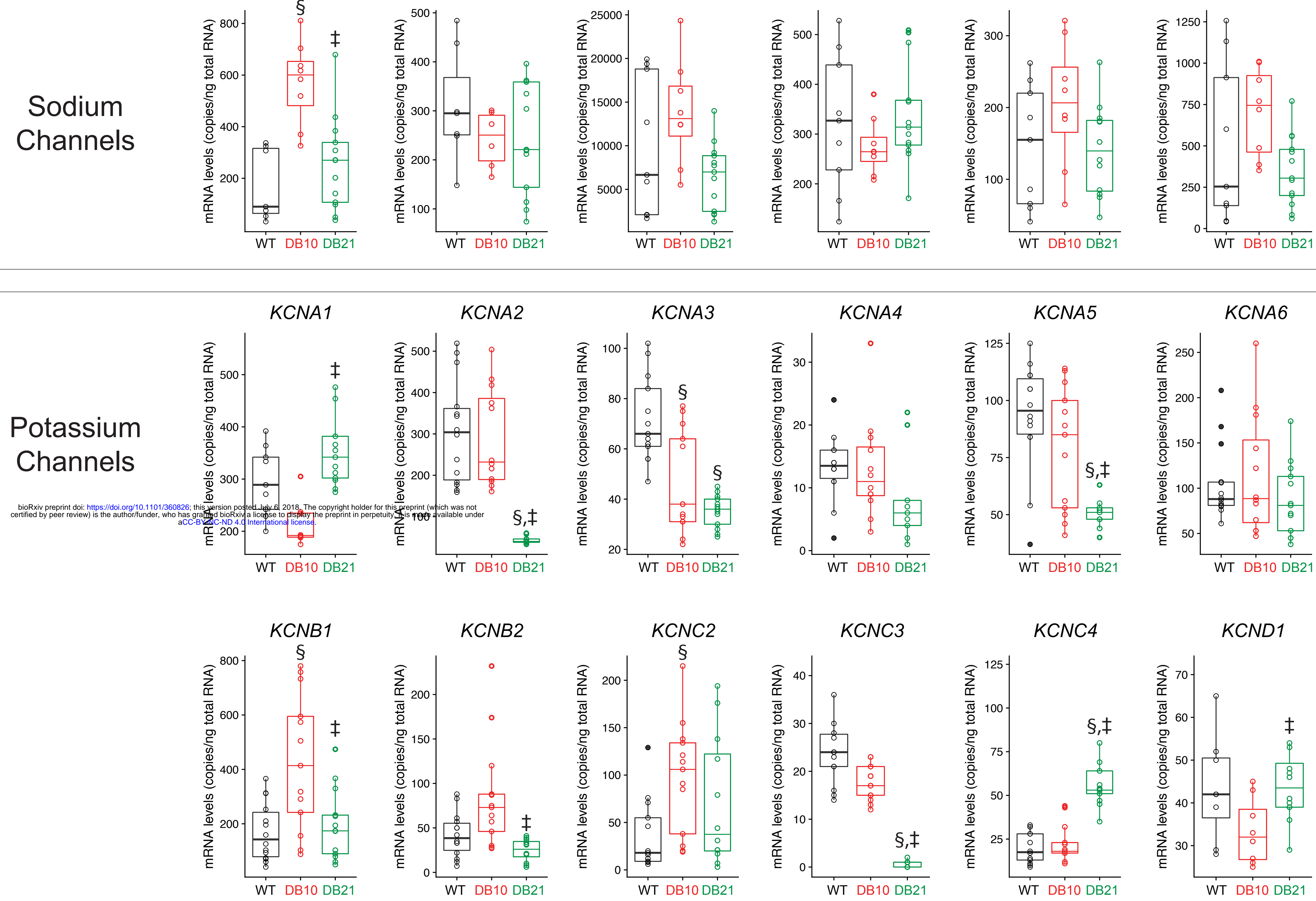

\section{$\S=$ diff from Control} $\ddagger=$ DB10 diff from DB21
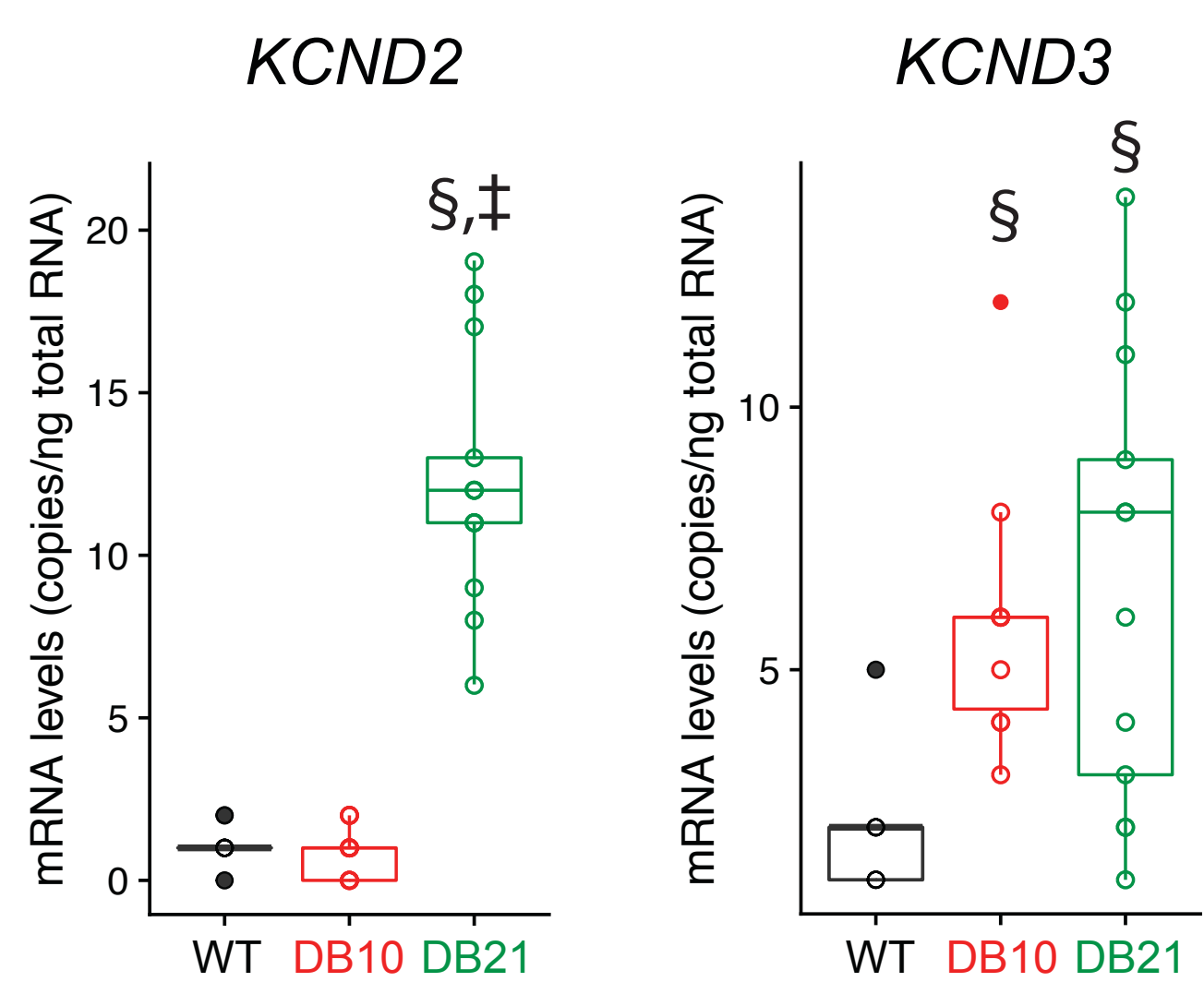

KCNN1

KCNN2

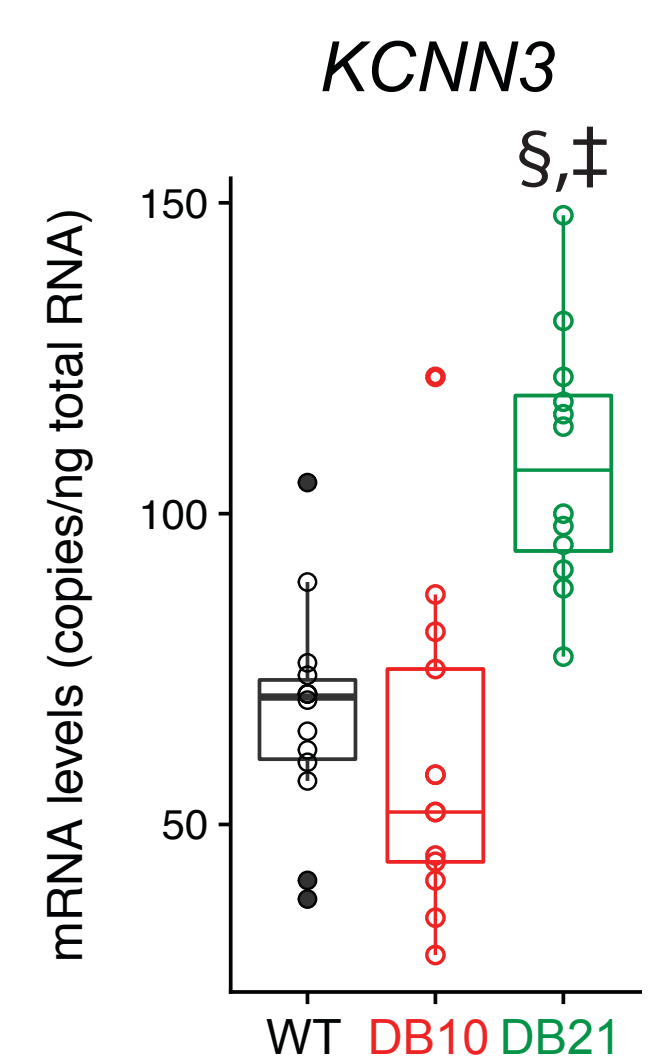

KCNMA1
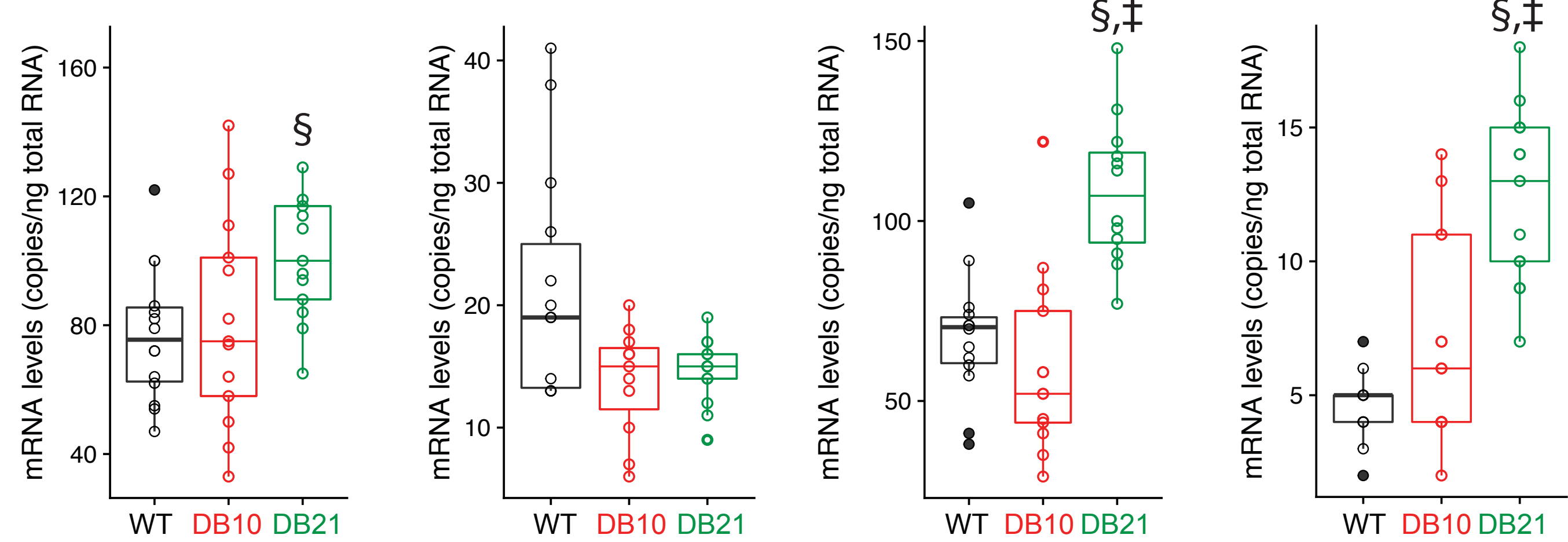
A.

\section{- Control \\ - DB10}

- DB21

biokxiv preprint doi: https://doi.org/10,1101/360826; this version posted July 6, 2018. The oppyright holder for this preprint (which was not
certified by peer review) is the author/funder, who has gorantertbioRxiva license to display the preprint in perpetuity. It is made available under
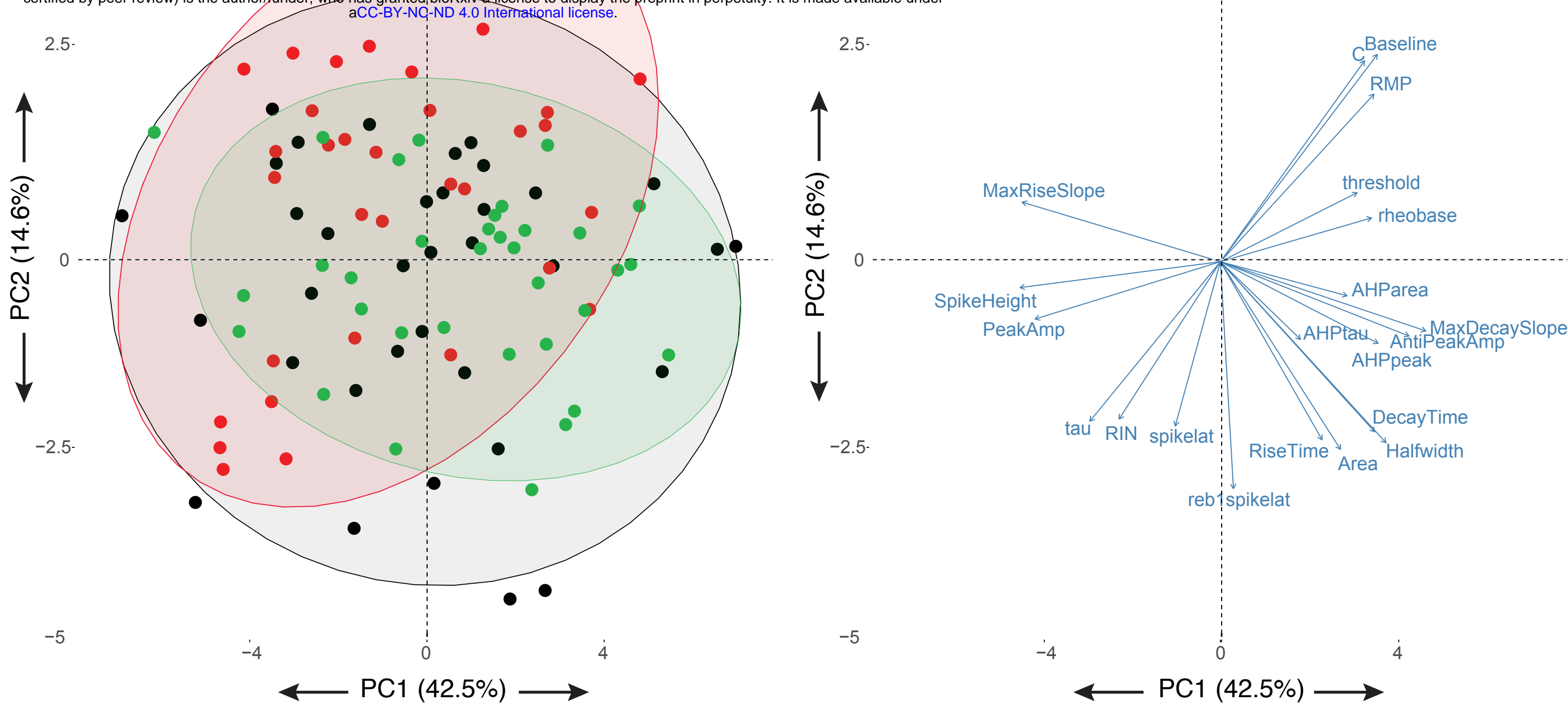

B.

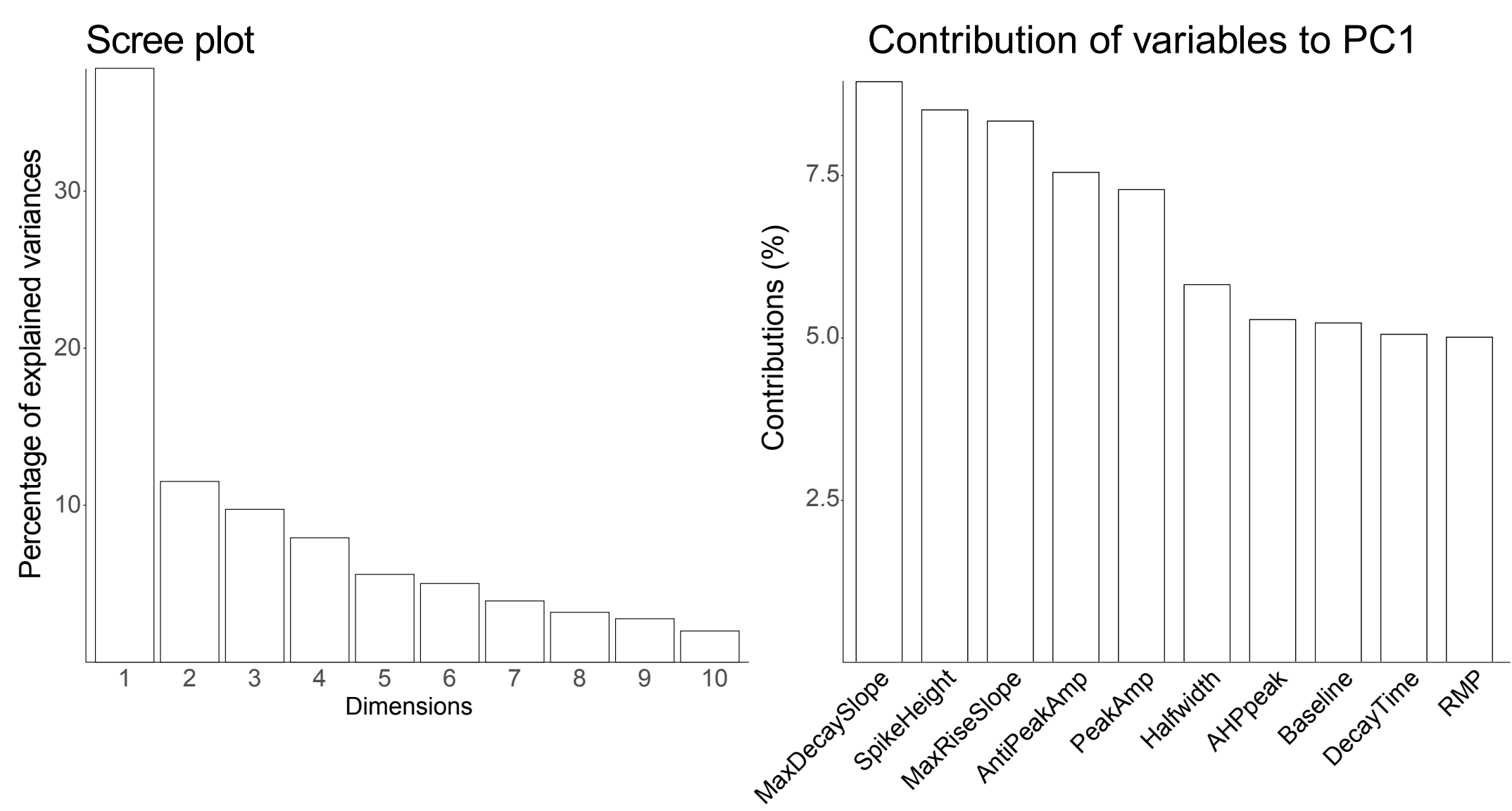


A.

Contro

DB10

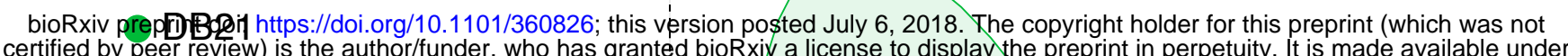
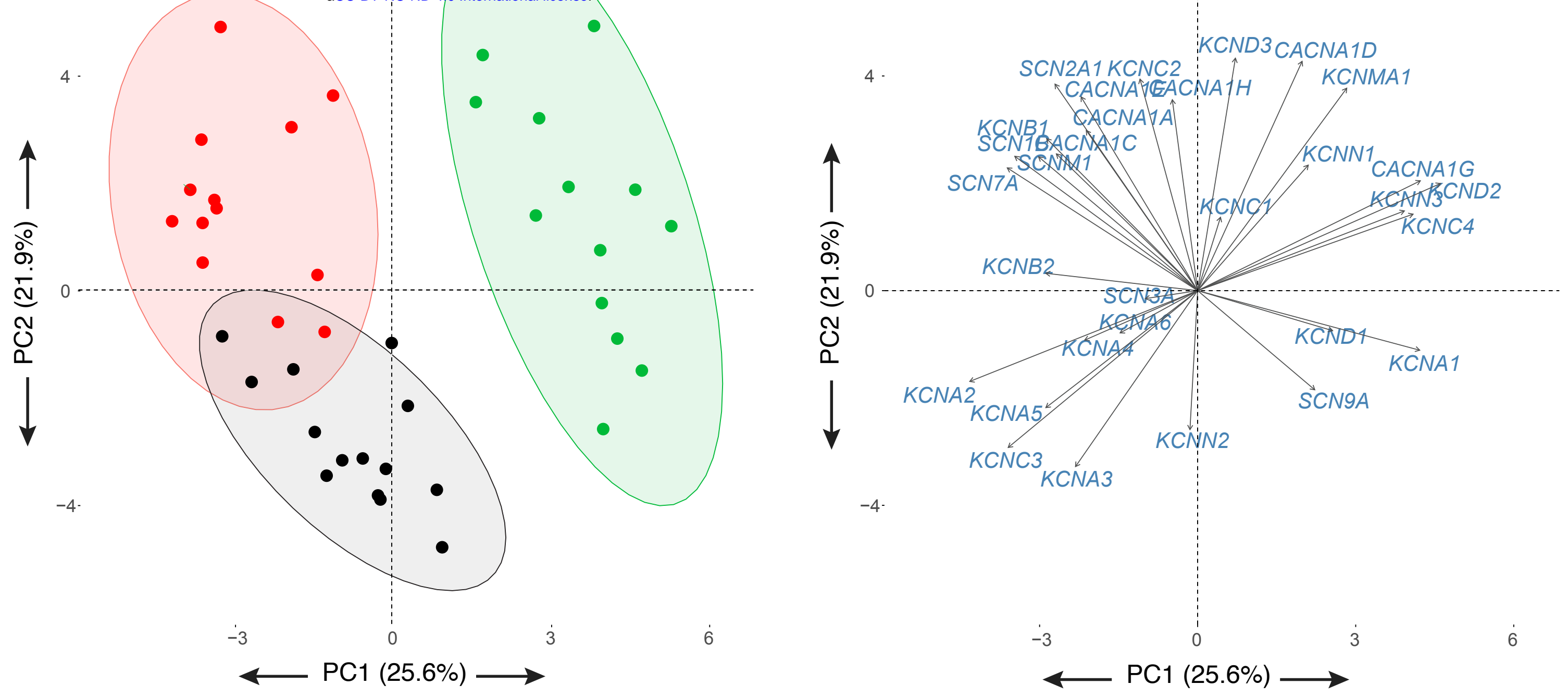

B.

Scree plot

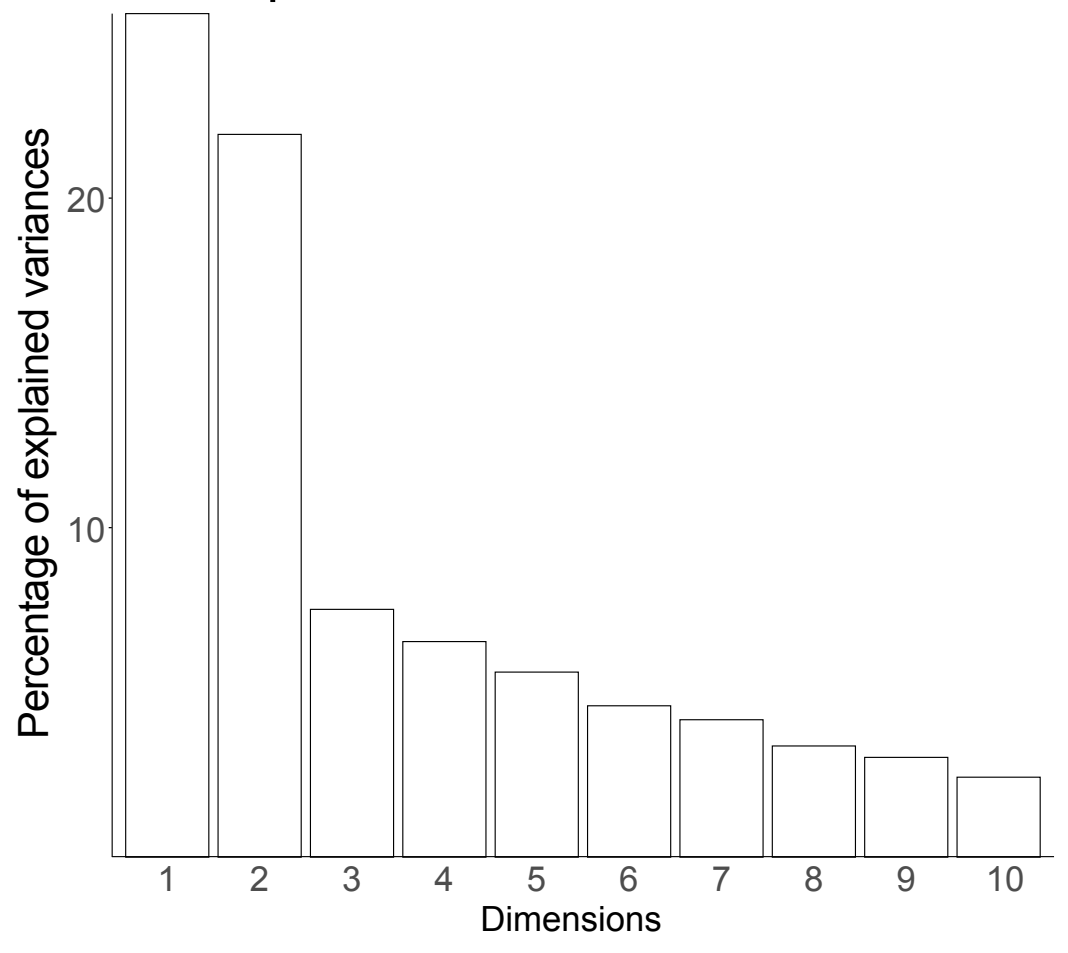

Contribution of variables to $\mathrm{PC} 1$

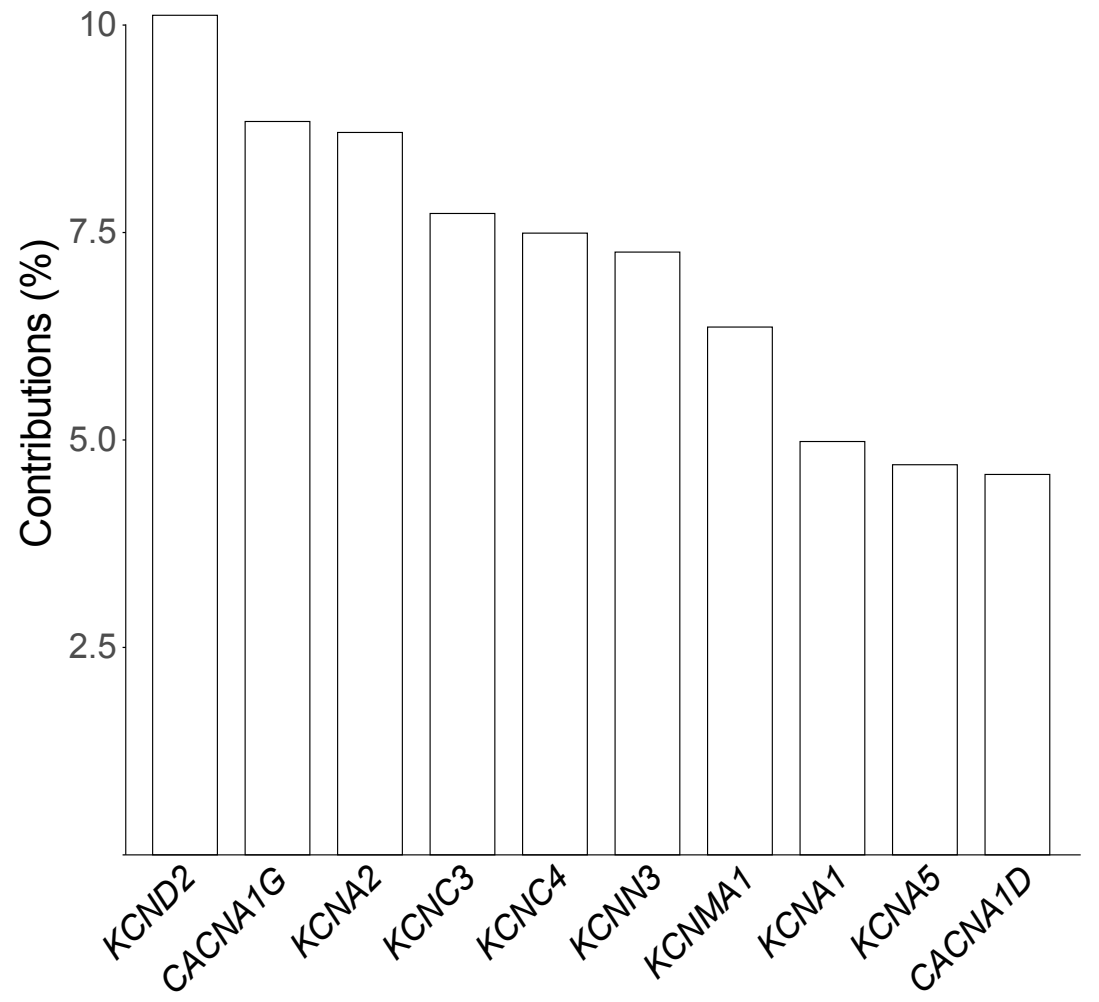

Contribution of variables to $\mathrm{PC} 2$

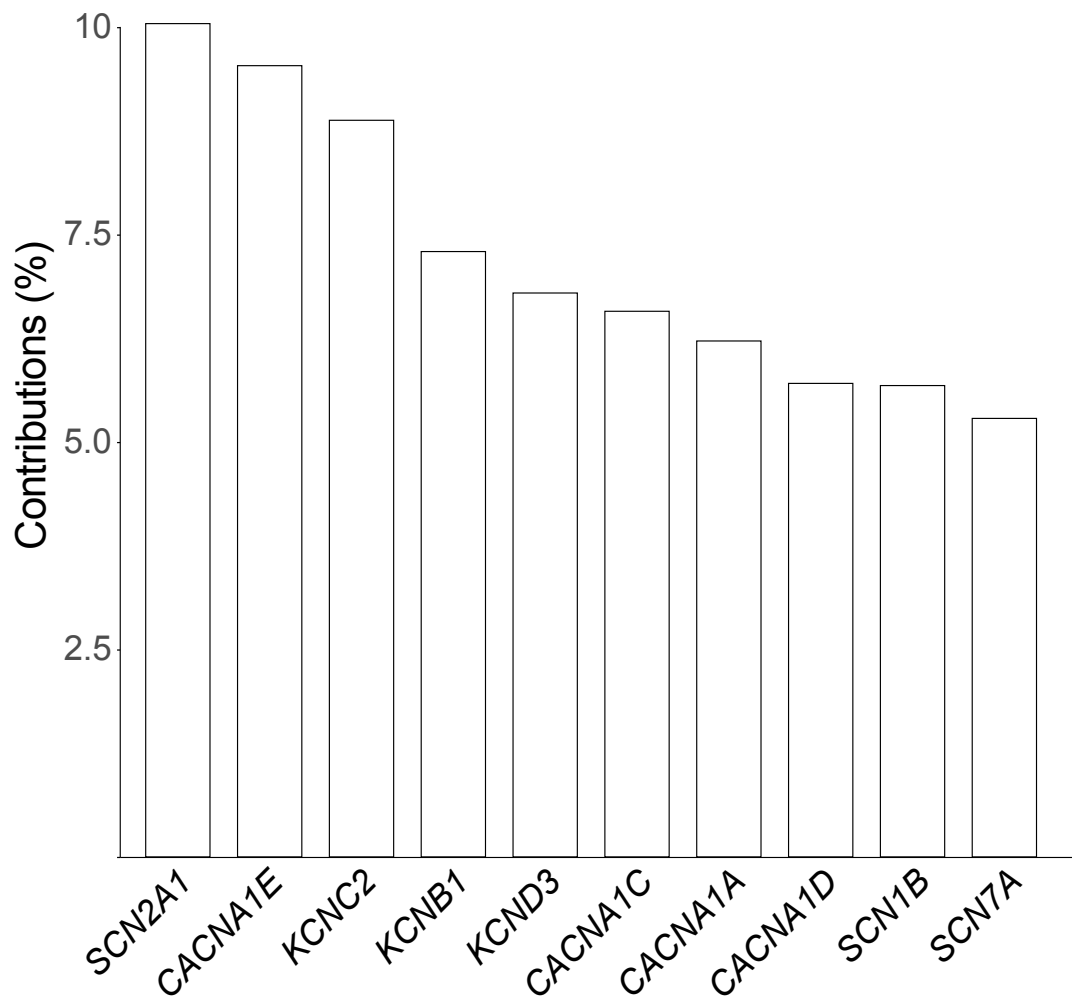

